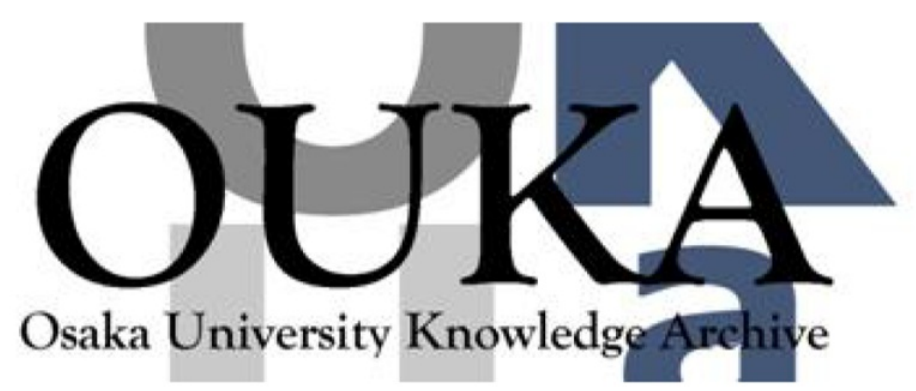

\begin{tabular}{|c|l|}
\hline Title & $\begin{array}{l}\text { The importance of government commitment in } \\
\text { attracting firms: A dynamic analysis of tax } \\
\text { competition in an agglomeration economy }\end{array}$ \\
\hline Author(s) & Kato, Hayato \\
\hline Citation & European Economic Review. 74 p. 57-p. 78 \\
\hline Issue Date & $2015-02$ \\
\hline oaire:version & AM \\
\hline URL & https://hdl.handle. net/11094/81781 \\
\hline rights & $\begin{array}{l}\text { O 2014 Elsevier B.V. This manuscript version is } \\
\text { made avai lable under the Creative Commons } \\
\text { Attribution-NonCommercial-NoDerivat ives 4. } 0 \\
\text { International License. }\end{array}$ \\
\hline Note & \multicolumn{2}{|l}{} \\
\hline
\end{tabular}

Osaka University Knowledge Archive : OUKA

https://ir. Library. osaka-u. ac. jp/

Osaka University 


\title{
The Importance of Government Commitment in Attracting Firms: A Dynamic Analysis of Tax Competition in an Agglomeration Economy
}

\author{
Hayato Kato * \\ First draft: January, 2014 \\ This version: October, 2014
}

\begin{abstract}
Agglomeration tendencies of industrial firms significantly affect the nature of tax competition. This paper analyzes tax competition between two countries over an infinite time horizon in an economy with trade costs and internationally mobile industrial firms. Most of the previous studies on tax competition in the 'new economic geography' framework employ static models. In this study, two governments dynamically compete with each other to attract firms through their choices of taxes and subsidies. It is shown that the commitment of the governments to their policies is crucial in determining the distribution of firms in the long run. Specifically, if governments find each others' tax policies credible, then one country will attract all the firms when trade costs are low enough to make agglomeration forces dominant. If policies are not credible, both countries may attract an equal share of firms even when trade costs are low, as the lack of commitment by governments acts as a dispersion force.

Keywords: Economic geography; Tax competition; Forward-looking behavior; Differential game; Commitment

JEL classification: F15; F22; H20; H30
\end{abstract}

* Graduate School of Economics, Hitotsubashi University, Naka 2-1, Kunitachi, Tokyo, 186-8601 Japan. Email address: ed132002@g.hit-u.ac.jp 


\section{Introduction}

Since the 1990s, low corporate tax rates have been a main driver for attracting foreign direct investment (FDI) and thereby promoting economic growth in some European countries such as Luxembourg and Ireland. Ireland is particularly noteworthy, as it drastically reduced its corporate income tax rate from $45 \%$ to $12.5 \%$ from 1998 to 2003 . This rate is much lower than that of other EU15 countries, which was 25\% in 2012. Due to this reduction, Ireland succeeded in hosting several multinational enterprises including Hewlett-Packard and Intel, and achieved a massive inflow of FDI. The geometric mean of the ratio of the net inflow of FDI to GDP in Ireland was 15.8\% from 1998 to 2003, far higher than that of other EU15 countries: 3.3\%(data are from UNCTAD). The success of Ireland seems to have fanned the fear of fierce tax competition among European countries, which had led to the international pressure on Ireland to raise its tax rate. France and Germany, for example, have requested Ireland to raise its taxes in return for its bailout rescue since 2010 (see, e.g. Mitchell (2009); Stewart (2011)). However, Ireland confirmed its commitment to the $12.5 \%$ tax rate and has since maintained this rate. Through this commitment, Ireland has tried to establish a reputation that it will continue to keep its tax rate low among rival countries.

The objective of this paper is to investigate how government commitment affects the location of industrial firms as a result of tax competition. In a symmetric two-country economy with agglomeration forces, I model the strategic interactions between two governments as an infinite-horizon dynamic game. The governments maximize their life-time payoffs through taxes and subsidies while considering the migration process of myopic firms. Assuming the governments care mostly about future payoffs and that they will agree on Pareto efficient locations, I examine two forms of commitment governments may make: full commitment and no commitment. The former corresponds to the open-loop Nash equilibrium while the latter corresponds the Markov-perfect Nash equilibrium. In the full commitment case, both governments announce a tax schedule over the entire horizon at the outset of the game and never change it. In the no commitment case, however, they choose their tax rate at each point in time by observing the current distribution of firms.

The results of tax competition dramatically change depending on whether or not commitment is possible. I find that tax competition with full commitment leads to the core-periphery configuration of firms when trade costs are low enough for the concentration of firms to sup- 
ply an ample tax base. This result can be explained by the fact that the governments face the situation known as 'battle of sexes'. The dispersed configuration where both the governments share firms evenly is too costly for them because they must provide negative taxes (or subsidies) to prevent firms with strong agglomeration motives from clustering into one country. Of course the core position where all firms are clustered is the most desirable for both governments. However, the peripheral position where no firms are located is better than the dispersed configuration because the government in the periphery does not have to subsidize firms and avoid the intense competition. Either country may become the core so that self-fulfilling expectations of both governments select the long-run outcome; the country that succeeds in convincing the counterpart will eventually attract all the firms. I also find that the tax competition without commitment may result in the dispersed configuration of firms even when trade costs are so low that benefits from agglomeration are large. Compared to the full-commitment case, the governments have more incentive to raise their tax rate because they know that the loss of firms from raising their own tax rate will be partially diminished by the reaction (i.e., tax increase) of the other. Both governments may set a higher tax rate while sharing firms evenly so that the dispersed pattern may be more desirable than the core status.

With these results, I draw the implication that, in the contemporary environment of deepening economic integration, effective tax competition relies critically on a government's commitment to its policies and its ability to convince foreign rivals that they will be implemented. This may explain the success of Ireland. But, at the same time, I also emphasize the weakness of commitment strategies. Credible policies imply that governments promise to keep their original policies even if they are aware that the policies are no longer optimal. Thus, such rigid policies are vulnerable to unexpected events such as sudden changes in the industrial location or policy changes in foreign rivals. When policymakers decide attitudes toward policies, it is worth recognizing the positive and negative aspects of such rigorous commitment.

\subsection{Related literature}

This paper draws from the literature on tax competition in an agglomeration economy. The 'new economic geography' formulates an imperfect competition trade model with mobile factors and trade costs, which is the so called 'core-periphery model'. This model demonstrates 
that as economic integration proceeds, which is modeled as falling trade costs, internationally mobile firms are more likely to cluster in one country. some researchers have studied the effects on firm locations of taxes strategically chosen by governments. Earlier contributions include Ludema and Wooton (200()); Kind et al. (200)(0); Andersson and Forslid (20(03); Baldwin and Krugman (2004). The main findings of the literature on agglomeration and tax competition are the superiority of the core country and a 'race to the top' (Baldwin and Krugman (2004); Borck and Pflüger (2006), among others); the ability of the core country to charge a higher tax rate, and the inverted U-shaped relationship of the tax differential in terms of trade costs between the core and periphery. ${ }^{2 / 2}$ For example, Baldwin and Krugman (2004) consider a Stackelberg game played by the core (leader) and peripheral country (follower), and show that, when trade costs are low, the industrial cluster brings about to the core a taxable rent ('agglomeration rent'). They also show that a decline in trade costs first increases and then decreases the tax gap. Borck and Pflüger (2006) confirm the result in a core-periphery model allowing for partial agglomeration. These results contrast with the conclusion of the standard neoclassical tax competition model that tax competition results in a 'race to the bottom' ${ }^{* 3}$ The existence of a taxable agglomeration rent is also supported by some empirical research (e.g., Charlot and Paty (2007) for French data; Coulibaly (20)8) and Brülhart et al. (2012) for Swiss data).

The conclusions of the previous studies crucially depend on the initial industrial locations. To avoid the difficulty of discontinuities in the reaction functions, which is a by-product of the core-periphery model, most existing studies assume that one country is the core from the beginning. Because policy implementation and firm migration are allowed to occur after the announcement of the policy in these models, the number of firms located in each country at the beginning of the game plays a decisive role in determining the equilibrium outcome. The advantages of the agglomerated position are thus assumed, and the strategic aspect of competition over mobile factors is not completely captured. Also, since the policy schedule consists of one tax rate, the effect of the government commitment to the policy cannot be fully examined.

\footnotetext{
*1 See Fujita and Thisse (2013) for a recent survey. Baldwin et al. (2003) focus more on policy issues including tax competition.

*2 Recent studies such as the work of Ottaviano and Ypersele (2005), which allows for the difference in size of immobile factors, and the work of Baldwin and Okubo (2014), which introduces firm heterogeneity in productivity, also observe the superiority of the core country.

*3 See Keen and Konrad (2012) for a comprehensive survey on tax competition in the neoclassical framework.
} 
This paper differs from the previous studies in that it considers tax competition in a fully dynamic context so as to treat agglomeration forces endogenously. By analyzing an infinitehorizon game, I avoid the difficulty of discontinuities and allow for all possible initial conditions in order to not be restricted to the core-periphery configuration. Moreover, by utilizing the differential game theory, I can analyze the impact of different forms of government commitment, which is not addressed in the previous studies. I show that, contrary to previous research, the core-periphery pattern may not emerge as a result of tax competition between governments without commitment. Even when the core-periphery pattern emerges in the full-commitment case, initially being the core is of little importance, as expectations of governments instead determine which country will be the core. However, the 'race to the top' result on the relationship between the core's tax rate and trade costs still holds whenever the core-periphery pattern emerges.

This paper is not the first to incorporate the forward-looking agent into the new economic geography framework (see, e.g.,Baldwin (2001); Ottaviano (2001); Ottaviano et al. (2002) Section 6; Oyama (2009a,b)). ${ }^{* 4}$ These studies deal only with the forward-looking behavior of industrial firms ${ }^{* 55}$ and do not model governments explicitly. In contrast, the present study allows only governments to be forward-looking agents. This paper and the studies just mentioned should be seen as complements because both try to investigate the role of far-sighted behavior but of different agents. In spite of this difference, one of the results I obtain that 'expectations matter' for equilibrium selection can be found in Baldwin (2001), Ottaviano (2001) and Ottaviano et al. (2002).

Dynamic aspects and commitment issues have been addressed in the literature of the standard tax competition without agglomeration forces (see, e.g., Janeba (2000); Keen and Konrad (2012), Section 2.3 and the references therein). The closest study in that field to this paper is Han et al. (2014). They consider an infinite-horizon tax game between two countries of unequal size. An asymmetric form of government commitment, which is not addressed in this paper, is assumed and the larger country adopts open-loop strategies while the smaller

*4 The first three consider the Krugman (1991) type of migration dynamics, where firms can move freely by paying costs determined by the current flow of migrants. The last one adopts Matsuyama (11991) type of migration dynamics, where only firms which receive an opportunity to revise their location choice can move without any costs. This paper and most of the studies in the new economic geography are in line with the myopic version of the Krugman (11991)'s dynamics.

*5 Oyama (2009a) discusses tax policy and points out that agglomeration rents should be much smaller because of the possibility of self-fulfilling coordinated migration, but the paper does not explicitly model governments. 
country adopts Markov-perfect strategies. They show that, if mobility of firms is high and the future payoff is important (as in this paper), the smaller country will lose all the firms in the long run. The result that a government without commitment will be the periphery is similar to one of the results I obtain. However, the model I present describes not only the conflict between governments but also the interaction among governments and firms with agglomeration motives. When considering the world economy in which FDI is motivated mainly by reducing transport costs and exploiting economies of scale (see, e.g., Markusen and Maskus (2002)), examining tax competition in the core-periphery model may be more relevant today than in the neoclassical world with constant returns to scale and perfect competition.

The rest of the paper proceeds as follows. The next section develops a simple general equilibrium model that induces agglomeration forces. Section 3 introduces governments and formulates a dynamic tax competition. The two equilibrium concepts in dynamic games, the open-loop Nash equilibrium (OLNE) and the Markov-perfect Nash equilibrium (MPNE), are also explained. The assumptions imposed on the analysis are also discussed. Section 4 presents the results whereby I characterize the stable steady state both under OLNE and under MPNE. Section 5 concludes.

\section{The model}

In this section, I consider the Ludema and Wooton (200) and Thisse (2010) version of the core-periphery model. The model may be viewed as the 'minimalist framework' of economic geography and has several distinctive features that make the analysis simple. First, the model follows the 'footloose entrepreneur' setting as in Forslid and Ottaviano (2003) whereby the manufacturing industry needs internationally immobile workers for variable inputs and mobile entrepreneurs for fixed inputs. Second, consumers' preferences are described by the quadratic quasi-linear utility function as in Ottaviano et al. (2002). Third, contrary to most of the core-periphery models, manufacturing firms produce a homogeneous product and engage in Cournot competition. Due to these simplifications, closed-form solutions can be obtained with a reduced number of parameters, though qualitative results are quite similar to the linear version of the core-periphery model by Ottaviano et al. (20)2). 


\subsection{The basic setup}

In this model, the economy consists of two countries (home, $h$, and foreign, $f$ ), two homogeneous goods (agricultural and manufactured goods), and two factors of production (workers and entrepreneurs). Total mass of workers in the world is $I>1$, and that of entrepreneurs is $L>1$. While workers are equally distributed between countries, the $100 \times \lambda$ percent of the entrepreneurs reside in country $h$ where $\lambda \in[0,1]$. The total population of country $i \in\{h, f\}$ becomes $S_{i}=I / 2+\lambda_{i} L$, where $\lambda_{h} \equiv \lambda$ and $\lambda_{f} \equiv 1-\lambda$.

The two types of factors are different in their place of employment and in their mobility. Each entrepreneur can move between countries and provides one unit of headquarter service with the manufacturing sector in the country where she resides, while each worker is immobile and provides one unit of labor service with the agricultural sector.

The agricultural sector is characterized by perfect competition and constant returns-to-scale technology. The goods are freely traded internationally without any trade costs. The price of the agricultural good is chosen as a numéraire, and only labor service by workers are required as variable inputs. The manufacturing sector, on the other hand, is characterized by imperfect competition and increasing returns to scale technology. The shipment of one unit of the manufactured good incurs an additional $\tau$ units of trade costs. To start a business, a potential firm in the sector hires one entrepreneur as a fixed input, but needs no variable inputs.

\subsection{Demand Side}

Every individual in country $h$ has the same preferences, and their utility function takes the following quasi-linear quadratic form: ${ }^{* 6}$

$$
u_{h}=\left[1-\frac{1}{2}\left(\frac{Q_{h}}{S_{h}}\right)\right]\left(\frac{Q_{h}}{S_{h}}\right)+\frac{Q_{h}^{a}}{S_{h}},
$$

where $Q_{h}\left(Q_{h} / S_{h}\right.$, respectively) is the total (per-capita, resp.) demand for the manufactured good and $Q_{h}^{a}\left(Q_{h}^{a} / S_{h}\right.$, resp.) is total (per-capita, resp.) demand for the agricultural good. Aggregating across individuals, total utility in the home country is given by the following:

$$
U_{h}=S_{h} u_{h}=\left[1-\frac{1}{2}\left(\frac{Q_{h}}{S_{h}}\right)\right] Q_{h}+Q_{h}^{a} .
$$

\footnotetext{
${ }^{* 6}$ In what follows, I concentrate on $h$. Symmetric expressions hold for $f$.
} 
The national budget constraint requires that the expenditure on the two goods equals the remuneration of production factors and the endowment of the numéraire good. I focus only on the case where $\bar{Q}^{a}$ is sufficiently large for the numéraire good to be consumed. Letting $p_{i}$ be the price of the manufactured good, $Y_{i}$ the total reward for factors, $\left.{ }^{*}\right]$ and $\bar{Q}_{h}^{a}$ the endowment of numéraire good, the national budget constraint can be written as follows:

$$
p_{h} Q_{h}+Q_{h}^{a}=Y_{h}+\bar{Q}_{h}^{a}
$$

The representative agent in country $h$ maximizes aggregate utility (2) subject to the national budget constraint (3) by choosing the total demand for the industrial good, $Q_{h}$. Optimization yields a linear-demand function for the manufactured product independent of income level:

$$
p_{h}=1-\frac{Q_{h}}{S_{h}}
$$

\subsection{Supply Side}

For the agricultural sector, perfect competition and costless trade lead to the equalization of price between countries. One unit of labor by worker produces one unit of the agricultural good so that its price denoted by $p_{i}^{a}$ and the wage of a worker denoted by $w_{i}^{a}$ in both countries are equalized to unity: $p_{h}^{a}=p_{f}^{a}=w_{h}^{a}=w_{f}^{a}=1$.

For the manufacturing sector, firms located in $i$ provide their goods to both domestic and foreign markets. Since an entrepreneur is needed to launch one industrial firm, country $h$ has $\lambda L$ firms and country $f$ has $(1-\lambda) L$ firms. The operating profit of a firm in $i$ can be written as follows:

$$
\pi_{h}=p_{h} q_{h h}+\left(p_{f}-\tau\right) q_{h f}
$$

where $q_{i j}$ denotes the amount of production by a firm in $i$, sold in $j(i, j \in\{h, f\})$. For the industrial good market to clear, it must hold that:

$$
Q_{h}=\lambda L q_{h h}+(1-\lambda) L q_{f h} .
$$

\footnotetext{
${ }^{* 7}$ As will be clear in the following discussion, suppose $w^{a}$ is the wage for a worker and $w$ for a entrepreneur, the reward to a worker is $w_{h}^{a}$ and the reward to a entrepreneur is $w_{h}$. Total reward to the factors in $h$ becomes $Y_{h}=w_{h}^{a} I / 2+w_{h} \lambda_{h} L$.
} 
Due to the separation of markets, firms can choose different quantities for each market given the inverse demand functions they face. As a result of Cournot competition, the market outcome is determined by a Nash equilibrium:

$$
q_{h h}^{*}=S_{h} p_{h}^{*}, \quad q_{f h}^{*}=S_{f}\left(p_{f}^{*}-\tau\right),
$$

where

$$
p_{h}^{*}=\frac{1+(1-\lambda) L \tau}{L+1} . \quad p_{f}^{*}=\frac{1+\lambda L \tau}{L+1} .
$$

The increase in the share of domestic firms and decline in trade costs make the domestic price go down.

For international trade to occur, trade costs must be low enough for the mill price $p_{f}^{*}-\tau$ to be positive whatever the distribution of firms may be:

$$
\text { Assumption 1. } \tau<\tau_{\text {trade }} \equiv \frac{1}{L+1} .
$$

This assumption holds throughout the analysis.

By substituting equilibrium prices and quantities into (4), the equilibrium operating profit can be calculated as follows:

$$
\begin{aligned}
\pi_{h}^{*} & =S_{h}\left(p_{h}^{*}\right)^{2}+S_{f}\left(p_{f}^{*}-\tau\right)^{2}, \\
& =\left(\frac{I}{2}+\lambda L\right) \cdot \frac{[1+(1-\lambda) L \tau]^{2}}{(L+1)^{2}}+\left(\frac{I}{2}+(1-\lambda) L\right) \cdot \frac{[1-\{1+(1-\lambda) L\} \tau]^{2}}{(L+1)^{2}} .
\end{aligned}
$$

Under Assumption 1, falling trade costs decrease the profits from the domestic market but increase those from the foreign market. Allowing for free entry and exit, the operating profit of a firm goes to the entrepreneur so that it becomes equal to the reward. Letting $w_{i}$ be the reward to an entrepreneur in $i$, it holds that $\pi_{i}^{*}=w_{i}$. Since there is one entrepreneur for every manufacturing firms, I refer to them interchangeably in what follows.

The utility of an entrepreneur in $h$ evaluated at the equilibrium prices and quantities is expressed as

$$
u_{h}^{*}=C S_{h}+w_{h}+\bar{q}^{a} .
$$

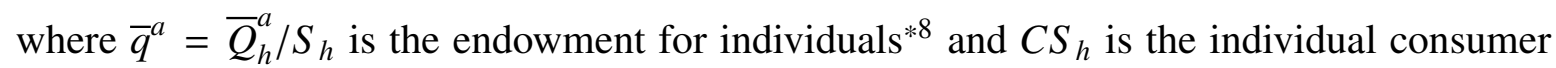

${ }^{* 8} \bar{q}^{a}$ is supposed to be sufficiently large for taxes, which will be introduced in the next section, to be paid. Further, $\bar{q}^{a}$ is assumed to be identical between countries so that it does not affect international differences in indirect utility. 
surplus:

$$
C S_{h}=\frac{L^{2}}{2(L+1)^{2}}[1-(1-\lambda) \tau]^{2} .
$$

$C S_{h}$ is increasing in the domestic firm's share, but is decreasing in trade costs as long as Assumption 1 holds. An entrepreneur, as a consumer, benefits from a lower price due to the expansion of the domestic firm's share.

\subsection{Location equilibrium}

The gap of the indirect utility, which determines the entrepreneurs' location choice, can be expressed as

$$
\begin{aligned}
\Delta u^{*}(\lambda) & \equiv u_{h}^{*}-u_{f}^{*} \\
& =C S_{h}+w_{h}-\left(C S_{f}+w_{f}\right) \\
& =Z\left(\lambda-\frac{1}{2}\right),
\end{aligned}
$$

where

$$
Z=\frac{L\left[2 L^{2}+(2 I+5) L+2(I+1)\right]}{(L+1)^{2}} \tau\left(\tau^{*}-\tau\right), \quad \tau^{*}=\frac{2(3 L+2)}{2 L^{2}+(2 I+5) L+2(I+1)} .
$$

Fig. 1 shows the relationship between $Z$ and trade costs. Parameter values are $L=1$ and $I=5$ so that I have $\tau_{\text {trade }}=0.5$.

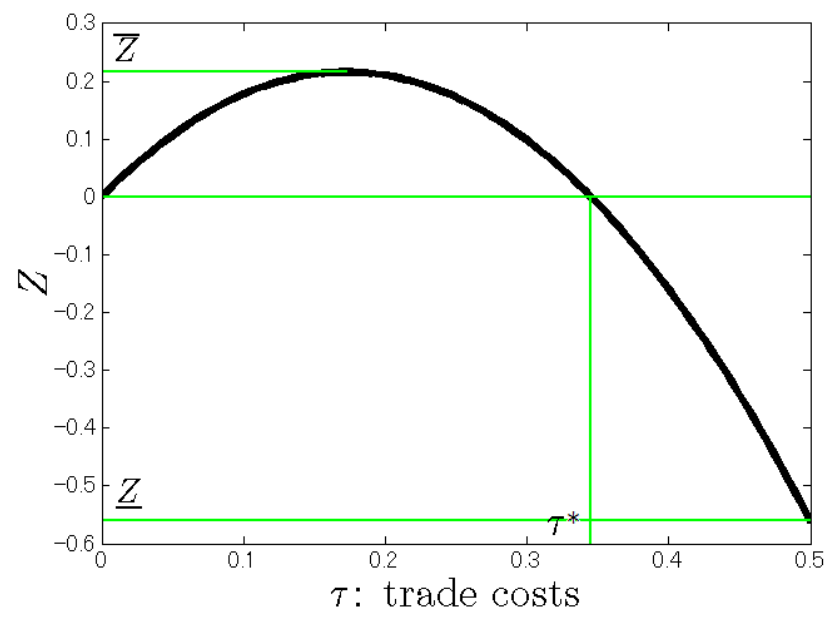

Fig. 1. Slope of the migration equation $Z$. 
$Z$ captures a firm's incentive to agglomerate (disperse, resp.) if it is positive (negative, resp.). Agglomeration forces reach the peak $(\bar{Z})$ when trade costs are intermediate $\left(\tau^{*} / 2\right)$, while they become smallest $(\underline{Z})$ when trade costs are highest $\left(\tau_{\text {trade }}\right)$. The intuition behind the inverted $U$-shaped relationship between $\tau$ and $Z$ is easy to grasp when considering the two extreme cases.. high, agglomeration of firms in one country is harmful because they earn little from the foreign market and operate solely in the domestic market. However, when $\tau=0$ and trade is completely free, agglomeration is not necessary because the location choice does not matter. When trade costs are intermediate, agglomeration is profitable. The positive utility difference between the core and periphery $\left(\Delta u^{*}(\lambda=1)=Z / 2\right)$ is the so called 'agglomeration rent'.

Following the tradition of the core-periphery model, I consider the myopic behavior of firms. That is, entrepreneurs, the owners of firms, relocate to the country that affords the higher current utility Therefore, the movement of firms is governed by a simple migration equation $\dot{\lambda} \equiv \mathrm{d} \lambda / \mathrm{d} t=\Delta u^{*}(\lambda)$. I simply assume that the motion stops if the economy hits either of the boundaries $\lambda \in\{0,1\}$. This restriction will be removed in the next section.

When $\tau>\tau^{*}$, the slope of the migration equation $Z$ is negative and the dispersed distribution $\lambda=1 / 2$ is stable, while when $\tau<\tau^{*}$, the slope is positive and the agglomerated distributions $\lambda \in\{0,1\}$ are stable. For the dispersed location to emerge, I impose the 'noblack-hole' condition:

$\begin{array}{ll}\text { Assumption 2. } & \tau^{*}<\tau_{\text {trade }} \\ & \Rightarrow L<\frac{1}{8}\left[2 I-5+\sqrt{(2 I-5)^{2}+32(I-1)}\right] .\end{array}$

The condition simply states that, to prevent agglomeration forces from being too strong, the number of entrepreneurs should be small compared to that of workers.

The following lemma is the central finding of the core-periphery model:

Lemma. If trade costs are high $\left(\tau>\tau^{*}\right)$, the symmetric configuration is the only stable one. If trade costs are low $\left(\tau<\tau^{*}\right)$, the core-periphery structure is the only stable one.

${ }^{* 9}$ Note that the difference of consumer surplus is increasing in $\tau$ as long as Assumption 1 holds: $\operatorname{CS}_{h}(\lambda=$ $1)-C S_{f}(\lambda=1)=L^{2} \tau(1-\tau) / 2(L+1)^{2}$. Note also that the wage gap has an inverted $U$-shaped relationship in terms of $\tau$ as long as $I>1$, Assumption 1 and 2 hold: $w_{h}(\lambda=1)-w_{f}(\lambda=1)=L \tau[2-(L+I+1) \tau] /(L+1)$. 
In this linear model, the 'break point' at which the symmetric state is no longer stable coincides with the 'sustain point' at which the concentrated states become stable.

\section{Tax competition over an infinite horizon}

Having presented the base model, I now introduce taxes and a government for each country that plays tax competition over an infinite time horizon. This section also explains equilibrium concepts in the dynamic game and includes a few additional assumptions.

\subsection{The governments' problem}

Following Ludema and Wooton (2000) and Borck and Pflüger (2006), taxes are levied in a lump-sum manner. The government in country $i \in\{h, f\}$ imposes lump sum taxes on each domestic firm so that the migration equation for firms is modified as follows:

$$
\begin{aligned}
\frac{\dot{\lambda}}{\gamma} & =\left(u_{h}^{*}-T_{h}\right)-\left(u_{f}^{*}-T_{f}\right) \\
& =Z\left(\lambda-\frac{1}{2}\right)-\left(T_{h}-T_{f}\right), \lambda \in[0,1],
\end{aligned}
$$

where $\gamma$ is a positive constant that represents the migration speed, and $T_{i}$ denotes the taxes in $i$ if it is positive or subsidies if negative. Unlike the previous section, hereafter, I do not require $\dot{\lambda}$ to be zero when $\lambda$ hits a boundary. The governments redistribute their tax revenues to the domestic immobile workers as numéraire goods so that the governments' budgets are balanced at each point in time.

Taking into account the firms' incentive to relocate, both governments try to maximize the following discounted sum of the instantaneous payoff $W_{i}$ :

$$
\begin{aligned}
& \max _{\left\{T_{i}(t)\right\}_{t=0}^{\infty}} \int_{0}^{\infty} \exp (-\rho t) W_{i}\left(\lambda(t), T_{i}(t)\right) \mathrm{d} t \equiv J_{i}, \\
& \text { s.t. }\left\{\begin{array}{l}
\dot{\lambda}(t) / \gamma=Z[\lambda(t)-1 / 2]-\left[T_{h}(t)-T_{f}(t)\right], \\
\lambda(t) \in[0,1], \lambda(0)=\lambda_{0} \text { given, }
\end{array}\right.
\end{aligned}
$$

where $\rho>0$ is a discount rate. Following Baldwin and Krugman (2004) and Borck and Pflüger (20(06), I adopt a simple instantaneous objective function:

$$
W_{i}\left(\lambda(t), T_{i}(t)\right) \equiv L \lambda_{i}(t) T_{i}(t)-\frac{k}{2} T_{i}^{2}(t)
$$


where $\lambda_{h} \equiv \lambda$ and $\lambda_{f} \equiv 1-\lambda$, and $k>0$ is a parameter. The first term on the right hand side is the total tax revenue for country $i$ and the second term is the quadratic loss from taxation. This simple instantaneous objective function captures the basic conflicts governments face: they seek to raise more tax revenue while maintaining a low tax rate. It is regarded as a reduced-form objective function that either selfish or benevolent governments adopt (Baldwin and Krugman (2004), Section 5). From a different point of view, the second term can be considered the administrative cost incurred in collecting taxes (see, e.g. Kenny and Winer (2006) for empirical evidence). The second term may also be interpreted as the costs of tax changes which are analogous to adjustment costs of price (e.g., Rotemberg (1982)) and investment (e.g., Summers (1981)). Since the model has a long time dimension, it would be reasonable to assume that an excessive tax increase or cut within a short period would be too costly and that governments prefer tax smoothing.

\subsection{Equilibrium concepts: Is commitment credible?}

This subsection introduces two equilibrium concepts, the open-loop Nash equilibrium (OLNE) and the Markov-perfect Nash equilibrium (MPNE). Intuitively speaking, OLNEs consider situations in which both governments can make a precommitment; they stick to their strategies announced at the beginning of the game. Conversely, MLNEs assume such a precommitment away, so both governments may deviate from their predetermined tax policies. Precommitment to tax schedules is possible in two coses. 100 One case is that the governments cannot observe the time path of the distribution of firms (except for the initial one) nor the tax path of the rival country. The other case is that the governments can observe the state and other player's actions but they can precommit to their future policies with the aid of commitment device such as national legislations with compelling power. In the context of tax competition, I adopt the latter explanation why precommitment is possible.

\footnotetext{
*10 The following explanation is based on Reynolds (1987) Section 3.

*11 It does not seem plausible that the actual governments adopt the open-loop strategies, but there are some countries that appear to do this. In particular, as discussed in Introduction, Ireland is a good example. A government report released in 2013 (Department of Finance of Ireland (2013)) firmly asserts the commitment toward its tax rate: "Our competitive taxation system is, of course, an element of the Irish package and we remain committed to our competitive $12.5 \%$ tax rate.'(p.3)
} 


\subsubsection{Open-loop Nash equilibrium}

In this model, an open-loop strategy for country $i$ is a tax policy $T_{i}$ which is a function of time and the boundaries of the state variable $\lambda \in\{0,1\}$. A pair of open-loop strategies $\left\{T_{h}^{o}(t, \lambda \in\{0,1\}), T_{f}^{o}(t, \lambda \in\{0,1\})\right\}$ forms an OLNE such that

$$
J_{i}\left(T_{i}^{o}, T_{j}^{o} ; \lambda\right) \geq J_{i}\left(T_{i}, T_{j}^{o} ; \lambda\right), \text { for every open-loop strategy } T_{i}(t, \lambda \in\{0,1\}), \quad i, j \in\{h, f\} ; i \neq j,
$$

where $J_{i}(\cdot, \cdot)$ is a maximized value of the objective function defined in (5). At an OLNE, the payoffs of both governments are maximized and neither has an incentive to deviate from its open-loop strategies, given the open-loop strategy of the other. To solve for OLNEs, the optimal control method can be applied. I formulate the current-value Hamiltonian for the home government $\mathcal{H}_{h}$ and the Lagrangian $\mathcal{L}_{h}$ as follows:

$$
\mathcal{H}_{h}=L \lambda T_{h}-\frac{k}{2} T_{h}^{2}+\mu_{h} \gamma\left[Z\left(\lambda-\frac{1}{2}\right)-\left(T_{h}-T_{f}\right)\right]
$$

and

$$
\mathcal{L}_{h}=\mathcal{H}_{h}\left(\lambda, T_{h}, T_{f}\right)+v_{h}^{1} \lambda+v_{h}^{2}(1-\lambda)
$$

where $\mu_{h}$ is the co-state variable associated with the state variable, and $v_{h}^{1}$ and $v_{h}^{2}$ are the Lagrange multipliers on the boundaries of the state variable. The optimal control problem here is somewhat different from the standard problem in that the state variable $\lambda$ should lie in between $[0,1]$. In order to deal with the state variable constraints, I employ 'Informal theorem' 4.1 in Hartl et al. (1995) (see, e.g., Oyama (2009b) for applications in economics). Given an open-loop strategy of the foreign government $T_{f}$, an open-loop strategy of the home government $T_{h}$ is characterized by the following necessary conditions for optimality:

$$
\begin{aligned}
& \frac{\dot{\lambda}}{\gamma}=Z\left(\lambda-\frac{1}{2}\right)-\left(T_{h}-T_{f}\right), \quad \lambda \in[0,1], \\
& \frac{\partial \mathcal{H}_{h}}{\partial T_{h}}=L \lambda-k T_{h}-\gamma \mu_{h}, \\
& \rho \mu_{h}-\dot{\mu}_{h}=\frac{\partial \mathcal{H}_{h}}{\partial \lambda}=L T_{h}+\gamma Z \mu_{h}, \\
& \lim _{t \rightarrow \infty} \exp (-\rho t) \mu_{h}=0, \\
& v_{h}^{1}(t)\left\{\begin{array}{ll}
>0 & \text { if } \lambda(t)=0 \\
=0 & \text { if } \lambda(t)>0
\end{array}, \quad v_{h}^{2}(t)\left\{\begin{array}{ll}
>0 & \text { if } \lambda(t)=1 \\
=0 & \text { if } \lambda(t)<1
\end{array},\right.\right.
\end{aligned}
$$


and for any time $s$ in a boundary interval and for any contact time $s, \stackrel{\text {,T2 }}{,} \mu_{h}(\cdot)$ may have a discontinuity governed by the following jump conditions :

$$
\begin{aligned}
& \mu_{h}\left(s^{-}\right)-\mu_{h}\left(s^{+}\right)=\eta_{h}^{1}(s)-\eta_{h}^{2}(s), \\
& \eta_{h}^{1}(s)\left\{\begin{array}{ll}
>0 & \text { if } \lambda(s)=0 \\
=0 & \text { if } \lambda(s)>0
\end{array}, \quad \eta_{h}^{2}(z)\left\{\begin{array}{ll}
>0 & \text { if } \lambda(s)=1 \\
=0 & \text { if } \lambda(s)<1
\end{array},\right.\right.
\end{aligned}
$$

for some $\eta_{h}^{1}(z), \eta_{h}^{2}(z)$ for each $s$, where $\mu_{h}\left(s^{-}\right) \equiv \lim _{t \rightarrow s^{-}} \mu_{h}(t)$ and $\mu_{h}\left(s^{+}\right) \equiv \lim _{t \rightarrow s^{+}} \mu_{h}(t)$. An open-loop strategy of $f$, given an open-loop strategy of $h$, is derived in a similar manner. I obtain an OLNE as a pair of tax policies that simultaneously satisfies both governments' necessary conditions for optimality just described.

OLNEs assume open-loop strategies, where both players announce the action schedule at the outset of the game and commit themselves to it. Because open-loop strategies depend on

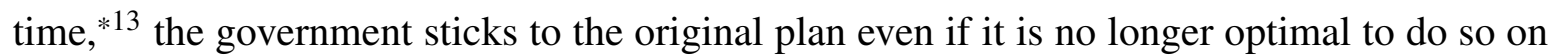
account of the counterpart's deviations from the original tax policy, or due to shocks that pull the distribution of firms off the predetermined path. Hence, an OLNE is not robust against any deviations from the equilibrium path.

\subsubsection{Markov-perfect Nash equilibrium}

A Markov-perfect strategy and a MPNE are defined similarly to the open-loop case. An Markov-perfect strategy for country $i$ is a tax policy $T_{i}$ which is a function only of the state variable $\lambda \in[0,1]$. An pair of Markov-perfect strategy $\left\{T_{h}^{m}(\lambda(t)), T_{f}^{m}(\lambda(t))\right\}$ forms an MPNE such that

$$
J_{i}\left(T_{i}^{m}, T_{j}^{m} ; \lambda\right) \geq J_{i}\left(T_{i}, T_{j}^{m} ; \lambda\right), \text { for every Markov-perfect strategy } T_{i}(\lambda(t)), \quad i, j \in\{h, f\} ; i \neq j,
$$

As in the open-loop case, I obtain an MPNE as a solution to the two governments' dynamic optimization problems. Necessary conditions for each government's problem here are slightly different from the ones in the open-loop case. Condition (6-3) is replaced with

*12 An interval $\left[t_{1}, t_{2}\right] \subset[0, \infty)$ with $t_{1}<t_{2}$ is said to be a boundary interval if $\lambda(t) \in[0,1]$ for all $t \in\left[t_{1}, t_{2}\right]$. An interval $\left(t_{1}, t_{2}\right) \subset[0, \infty)$ with $t_{1}<t_{2}$ is said to be an interior interval of $\lambda(\cdot)$ if $\lambda(t) \in(0,1)$ for all $t \in\left(t_{1}, t_{2}\right)$. If the trajectory is in the interior interval just before and just after $s, s$ is said to be a contact time.

*13 The open-loop strategies we consider are slightly different from the standard one; the former depends both on time and the boundaries of the state variable, whereas the latter depends only on time. However, the argument does not change much. 
the following condition:

$$
\begin{aligned}
\rho \mu_{h}-\dot{\mu}_{h} & =\frac{\partial \mathcal{H}_{h}}{\partial \lambda}+\frac{\partial \mathcal{H}_{h}}{\partial T_{f}} \frac{\partial T_{f}}{\partial \lambda} \\
& =L T_{h}+\gamma Z \mu_{h}+\gamma \mu_{h} \frac{\partial T_{f}}{\partial \lambda} .
\end{aligned}
$$

The necessary conditions from (6-1) to (6-7) other than (6-3) are the same. Symmetric expressions hold for the foreign government.

The second term in the right hand side of (7) captures the feedback effect of the counterparts on the change of the state variable. In the Markov-perfect case, the government takes into account how the other government changes its tax policy by responding to the changes of the distribution of firms. In the open-loop case, the government ignores this feedback effect so that the term does not appear.

Since the government utilizes the counterpart's decisions at each point in time, a credible precommitment for implementing the tax schedule determined at the beginning of the game is no longer possible. Markov strategies that depend only on the state variable in the game imply that the governments optimally choose their tax schedules at each time instant. Thus, an MPNE is a subgame perfect equilibrium and is robust against any deviations from the equilibrium path. 14

\subsubsection{Assumptions}

The subsequent analysis relies on several assumptions. First, to shed light on the dynamic aspect of the analysis, I assume the following:

Assumption 3. $\rho / \gamma$ is sufficiently close to zero.

The ratio of the governments' discount rates to the migration speed $\rho / \gamma$ is called the 'degree of friction'. The behavior of the dynamics does not depend on $\rho$ or $\gamma$ independently (see Appendices for details), but on the ratio. This assumes that the governments greatly value the future (small $\rho$ ) and/or the firms move quickly when responding to the tax differential (large $\gamma$ ). Thus, when deciding tax policies, the governments put more emphasis on the steady states where movement of firms stops, than on the short term payoffs on the way to the steady states.

*14 Both solution concepts are time consistent, which is a weaker requirement than the subgame perfectness. See Dockner et al. (200) Ch. 4. 
Second, I need a criterion to select the resulting outcomes among others because, as will be seen in the analysis, the model has multiple stable steady states:

Assumption 4. Pareto inefficient steady states for governments (if any) are eliminated.

This refinement of the Nash equilibrium is known as 'payoff dominance' (without uncertainty). Since the governments focus solely on the steady-state payoffs due to Assumption 3, the resulting outcomes are determined by the steady-state payoffs. If the payoff at a stable steady state dominates the others in a Pareto sense, both governments agree that the economy reaches the state.

Finally, for analytical convenience, I restrict the range of parameter $k$, which captures the intensity of loss from an increasing tax or subsidy rate:

$$
\text { Assumption 5. } 0<k<\frac{(2-\sqrt{3}) L}{\bar{Z}} \approx \frac{0.27 L}{\bar{Z}}, \quad \bar{Z} \equiv \max Z=\frac{L(3 L+2)^{2}}{(L+1)^{2}\left[2 L^{2}+(2 I+5) L+2(I+1)\right]}
$$

This assumption eliminates the imaginary root in the linear MPNE (see Appendix B for details).

\section{Results}

This section characterizes the resulting industrial location both under OLNE and under MPNE. The time path of the share of industry and taxes are also discussed.

\subsection{Open-loop case: Both governments fully commit to their tax sched- ules}

I illustrate OLNEs by resorting to intuitive arguments, which are verified by the formal proof in Appendix A. The present model is somewhat complicated because the economy by nature may have multiple steady states, the symmetric state $\lambda=1 / 2$ and the concentrated states $\lambda \in\{0,1\}^{15}$ However, since the future is sufficiently important for the governments by Assumption 3, the governments are concerned mainly with the steady-state payoffs when choosing equilibrium paths. Assumption 4 requires that the steady state configurations which

*15 Since the migration equation is linear with respect to $\lambda$, the interior points, other than the symmetric state, cannot be steady states. 
bring higher payoffs to both governments than others are realized in equilibrium. By comparing the payoffs between the symmetric state and the concentrated states, the resulting steady states can be found. The stability of the states are proved in Appendix A.

First, I look at the symmetric steady state, which can be obtained by making $\dot{\lambda}=\dot{\mu}_{h}=\dot{\mu}_{f}=$ 0 and $v_{h}^{1}=v_{h}^{2}=v_{f}^{1}=v_{f}^{2}=0$ in the necessary conditions. Since both governments have an equal share of firms at the steady state, the tax rate will be equalized as a result of dynamic competition:

$$
T_{h}^{o}\left(\lambda^{o}=\frac{1}{2}\right)=T_{f}^{o}\left(\lambda^{o}=\frac{1}{2}\right)=\frac{L(\rho-\gamma Z)}{2[k \rho+\gamma(L-k Z)]} .
$$

The expression is simplified by Assumption 3 that the degree of friction $\rho / \gamma$ is sufficiently close to zero:

$$
T_{h}^{o}\left(\lambda^{o}=\frac{1}{2}\right)=T_{f}^{o}\left(\lambda^{o}=\frac{1}{2}\right)=\frac{L Z}{2(k Z-L)}\left\{\begin{array}{ll}
\geq 0 & \text { if } Z \leq 0 \\
<0 & \text { if } Z>0
\end{array} .\right.
$$

Note that, by Assumption 5, $k$ is small enough for the denominator to always be negative. The inverted U-shaped relationship between the slope of the migration equation $Z$ and trade $\operatorname{costs} \tau$ (Fig. 1) implies that positive (negative, resp.) $Z$ equals high trade $\operatorname{costs} \tau>\tau^{*}$ (low trade costs $\tau<\tau^{*}$, resp.).

It can be easily verified that if trade costs are high $\left(\tau>\tau^{*}\right)$, making the dis-intensive to agglomerate strong $(Z<0)$, the tax rate is positive and both governments earn positive payoffs at the symmetric steady state. On the other hand, if trade costs are low $\left(\tau<\tau^{*}\right)$, making the incentive to agglomerate strong $(Z>0)$, the tax rate is negative and both governments incur loss by providing subsidies to keep the symmetric location stable.

To see why the tax rate responds to trade costs as such, consider the motives of firms. High trade costs lessen the profitability of export and make the domestic competition among firms tougher so that firms try to avoid a country with many competitors. Because of the firms' preference for diversified distribution, the governments can impose positive tax. Conversely, low trade costs reverse the outcome: since low trade costs makes export more profitable, firms try to locate in a country with many rivals in order to exploit scale economies. The governments need to subsidize the domestic firms to prevent them from moving away. This is reminiscent of the 'race to the bottom' result. Strong incentives for firms to gather make the symmetric configuration unattractive for both governments.

Next, I look at the steady state with full agglomeration in the home country $(\lambda=1)$. For 
the concentrated configuration to be stable, the tax differential should be determined in such a way that the motion of firms $\dot{\lambda}$ evaluated at $\lambda=1$ is equal to zero and $T_{h}-T_{f}=Z / 2$. Evidently, the optimal tax rate for country $f$ is zero and it has zero payoff. Therefore, the core country will set its tax rate at $Z / 2$ :

$$
\begin{aligned}
& T_{h}^{o}\left(\lambda^{o}=1\right)=\frac{Z}{2} \\
& T_{f}^{o}\left(\lambda^{o}=1\right)=0 .
\end{aligned}
$$

Both the tax rate and the payoff of country $h$ at the steady state are negative under low agglomeration incentive $Z<0$ and equivalently high trade costs $\tau>\tau^{*}$, whereas they are positive under high agglomeration incentive $Z>0$ and low trade costs $\tau<\tau^{*}$.

The same reasoning for the symmetric case applies here. High trade costs strengthen the incentive for firms to diversify so that the core country has to subsidize them to maintain clustering. Under low trade costs, however, the incentive to concentrate is so strong that the core earns the taxable agglomeration rent.

Fig. 2-(a) shows the tax rate of $h$ at each steady state for a various level of trade costs. 16 The instantaneous payoff of $h$ also exhibits a similar shape as in Fig. 2-(b). Parameter values are $L=1, I=5$, and $k=1$. By the symmetry of the model, it holds that $T_{h}^{o}\left(\lambda^{o}=1\right)=$ $T_{f}^{o}\left(\lambda^{o}=0\right), T_{h}^{o}\left(\lambda^{o}=0\right)=T_{f}^{o}\left(\lambda^{o}=1\right)$ and $T_{h}^{o}\left(\lambda^{o}=1 / 2\right)=T_{f}^{o}\left(\lambda^{o}=1 / 2\right)$. The same relations hold for the payoffs of country $f$.

*16 Haufler and Wooton (2010) study a static tax game in a location model ('footloose capital model') which is similar to the present model. Their model also obtains a U-shaped relationship with the tax rate and trade costs in the symmetric equilibrium. But their paper and this paper are quite different in that their model exhibits weaker agglomeration forces and their focus is only on interior equilibria. 
(a)

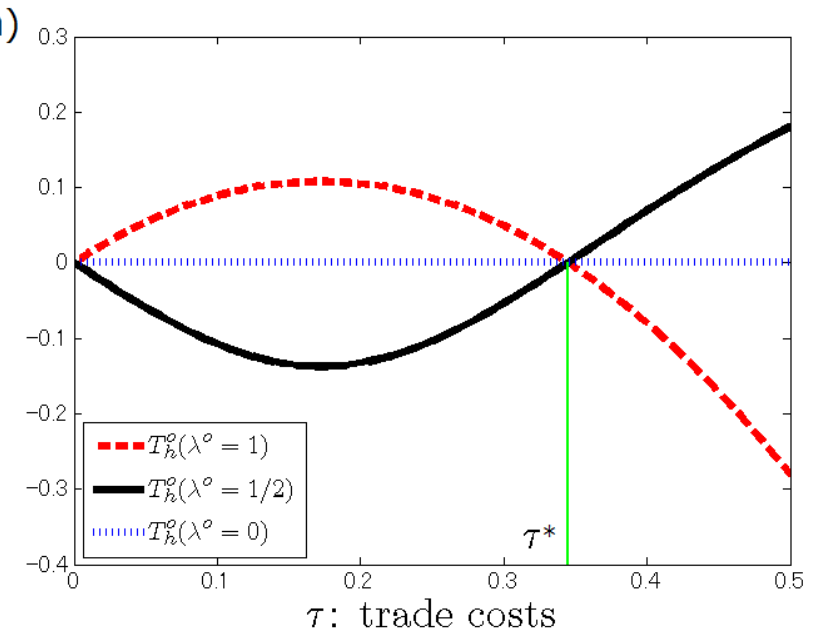

(b)

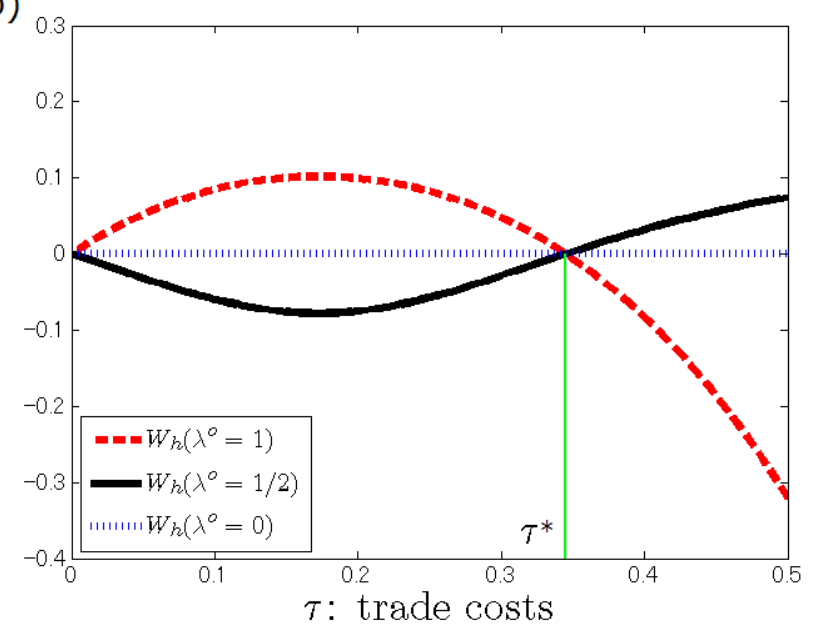

Fig. 2. Country $h$ 's (a) tax rate and (b) payoff at the steady state under OLNE.

To sum up, high trade costs bring the dispersed equilibrium $\lambda=1 / 2$, while low trade costs bring the agglomerated equilibrium $\lambda \in\{0,1\}$. When trade costs are high $(Z<0)$, the governments share the equal number of firms while setting a positive tax rate by taking advantage of the firms' anti-agglomeration motive. Since the governments have to provide subsidies to keep all the firms in their country, neither of them tries to achieve agglomeration. In contrast, when trade costs are low $(Z>0)$, the governments have to set negative tax rates to maintain the symmetric configuration because of the firms' agglomeration motive and instead they try to become the core. In this case, the governments face a 'battle of sexes' situation. 
Although both governments prefer the core-periphery patterns to the dispersed one, they have a conflict of interests over which of them attains agglomeration. As in the battle of the sexes game, the winner of tax competition cannot be determined in the model. These findings reveal that the result of tax competition dramatically changes below and above the threshold, which is called the 'bifurcation of tax competition' 10 The diversified distribution of firms emerges when $\tau>\tau^{*}$, and the concentrated distribution emerges when $\tau<\tau^{*}$. Thus, I obtain the following proposition: $: \frac{18}{}$

Proposition 1. The OLNEs are characterized in the following way (except for the nongeneric case: $\tau=\tau^{*}$ or $Z=0$ )

(i) If trade costs are high $\left(\tau>\tau^{*}\right.$ or $\left.Z<0\right)$, the symmetric configuration is the only stable steady state and the tax rates at the steady state are given by

$$
T_{h}^{o}\left(\lambda^{o}=\frac{1}{2}\right)=T_{f}^{o}\left(\lambda^{o}=\frac{1}{2}\right)=\frac{L Z}{2(k Z-L)} .
$$

(ii) If trade costs are low $\left(\tau<\tau^{*}\right.$ or $\left.Z>0\right)$, the only stable steady states are in the coreperiphery configuration and the tax rates at the steady states are given by

$$
\begin{gathered}
\text { Case } \lambda^{o}=0: T_{h}^{o}\left(\lambda^{o}=0\right)=0, \quad T_{f}^{o}\left(\lambda^{o}=0\right)=\frac{Z}{2}, \\
\text { or } \\
\text { Case } \lambda^{o}=1: T_{h}^{o}\left(\lambda^{o}=1\right)=\frac{Z}{2}, \quad T_{f}^{o}\left(\lambda^{o}=1\right)=0 .
\end{gathered}
$$

Proof. See Appendix A. It can be readily verified that the static analysis in the same setting mimics the results in Proposition 1 (see Section 4.3).

Proposition 1 confirms the 'race to the top' result from Baldwin and Krugman (2004) in a dynamic context. When trade costs are low, the core country eventually hosts all the firms while setting a positive tax rate. The tax gap between the core and periphery $\left(T_{h}^{o}\left(\lambda^{o}=1\right)-\right.$ $\left.T_{f}^{o}\left(\lambda^{o}=1\right)=Z / 2\right)$ exhibits a inverted U-shaped curve as in the dashed line in Fig. 2-(a). In contrast to their sequential move game, any initial location is allowed and the initial advantage

\footnotetext{
${ }^{* 17}$ I am grateful to Richard Baldwin for naming this.

*18 If trade costs happen to be the critical value $\tau^{*}$, the slope of the migration equation $Z$ equals zero and any distribution is stable. But this particular case is unimportant.
} 
would disappear in the dynamic model. The country that becomes the core is determined by 'expectations' of governments, not by 'history' of industrial locations. An analogous argument can be found in the studies on the forward-looking behavior of entrepreneurs in the core-periphery model (Baldwin (2001); Ottaviano (2001); Ottaviano et al. (2002), Section 6). ${ }^{* 19}$ Consider why the peripheral country fails to attract firms even when competition lasts an infinite time. Even if the peripheral country, say $f$, took back all the firms and achieved the core position $\left(\lambda=0, T_{h}=0\right.$ and $\left.T_{f}=Z / 2\right)$, it could not commit itself to keep its tax rate low enough to make the distribution of firms stable. $f$ would have an incentive to increase its tax rate after catching all the firms. Thus, it could not stop firms from relocating to the other country. $\frac{\sqrt{20}}{20}$

Fig. 3 shows the transition path from the initial state to the steady state with high trade costs $(\tau=0.2$ in Fig.3-(a)) and low trade costs $(\tau=0.4$ in Fig. 3-(b)). Initial distributions of firms are $\lambda_{0}=0.7$ in (a) and $\lambda_{0}=0.3$ in (b), Other parameter values are $L=1, I=5, k=1$ and $\rho / \gamma=0$. In Fig. 3-(a), trade costs are higher than the bifurcation of tax competition $\left(\tau=0.4>0.3448=\tau^{*}\right)$. Country $h$, which has more firms at the beginning, will decrease its tax rate gradually, while country $f$, which has fewer firms, will behave in the opposite way. In Fig. 3-(b) where trade costs are low enough $\left(\tau=0.2<0.3448=\tau^{*}\right)$, a more spectacular change is observed. The prospective core country, $h$, reduces taxes excessively at the outset and raises taxes as more firms relocate in $h$.

*19 Oyama (2009a,b) also examine the forward-looking expectations of entrepreneurs. In contrast to the three papers cited in the text, these two papers obtain the uniqueness of stable steady state in a more general coreperiphery model with asymmetries of market size and trade costs.

*20 Mathematically, the discussion here corresponds to the choice of the Lagrange multipliers $v_{i}^{1}$ and $v_{i}^{2}$ on the boundaries of the state variable. In steady states, the state and co-state (or control) variables are constant over time $\left(\dot{\lambda}=\dot{\mu}_{h}=\dot{\mu}_{f}=0\right)$. The multipliers are uniquely determined so as to attain a steady state. Since the multipliers cannot be chosen in such a way that both the two concentrated states are steady states at the same time, either one of the steady states is achieved. 
(a)

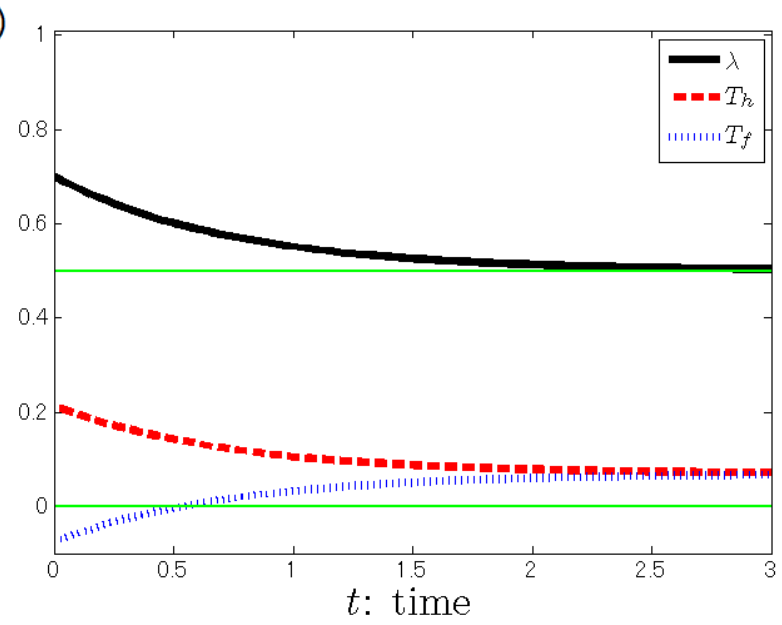

(b)

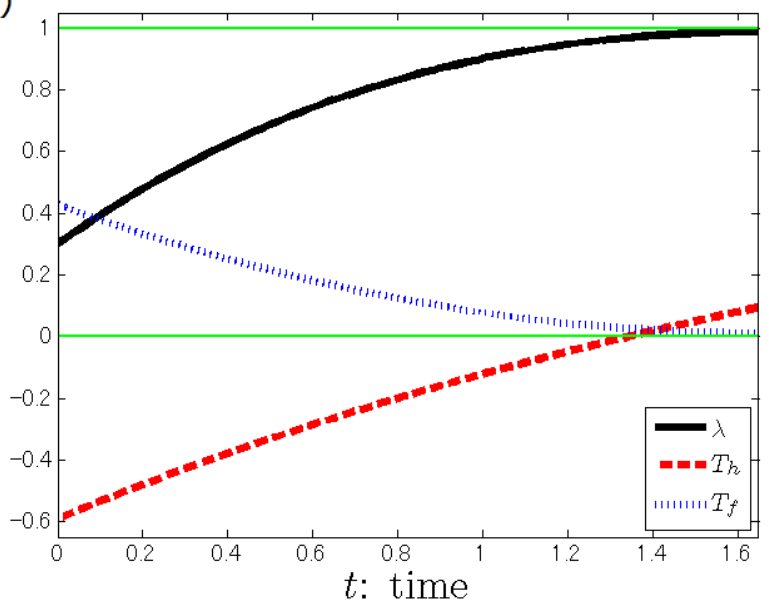

Fig. 3. Transition path under OLNE with (a) high trade costs and (b) low trade costs.

It is worthwhile to mention the limitation of OLNE. An OLNE is not subgame perfect and is fragile to any unexpected events. Suppose that unanticipated shocks happen at a point in time and thereby alter the path of $\lambda$ from that time onwards that both governments have expected. Although the original tax schedule that both governments announced at the initial stage of the game is no longer optimal, they will stick to the original tax schedules. In the case of Ireland discussed in Introduction, its aggressive tax policies have been effective for attracting FDI at the expense of the flexibility. 


\subsection{Markov-perfect case: Neither government commits to its tax sched- ule}

I turn to the analysis of MPNE. Only the symmetric linear strategy with respect to the state variable is considered:

$$
\begin{aligned}
& T_{h}(\lambda)=a \lambda+b_{h}, \\
& T_{f}(\lambda)=a(1-\lambda)+b_{f},
\end{aligned}
$$

where $a, b_{h}$ and $b_{f}$ are constants that are determined in equilibrium.

As in the preceding analysis, consider the tax rate and payoff both at the symmetric and concentrated steady states. In the later case, the tax rate is determined so as to keep the coreperiphery structure stable: the core country sets its rate at $Z / 2$, while the peripheral country sets at zero. Since the smaller $Z$ makes the tax rate lower, the concentrated steady states cannot be realized as long as $Z<0$ or $\tau>\tau^{*}$.

The tax rates at the symmetric steady state are calculated as follows:

$$
\begin{aligned}
& T_{h}^{m}\left(\lambda^{m}=\frac{1}{2}\right)=\frac{L\left(Z-\frac{\partial T_{f}}{\partial(1-\lambda)}\right)}{2\left[k\left(Z-\frac{\partial T_{f}}{\partial(1-\lambda)}\right)-L\right]}, \\
& T_{f}^{m}\left(\lambda^{m}=\frac{1}{2}\right)=\frac{L\left(Z-\frac{\partial T_{h}}{\partial \lambda}\right)}{2\left[k\left(Z-\frac{\partial T_{h}}{\partial \lambda}\right)-L\right]}
\end{aligned}
$$

Unlike the open-loop case, the tax rates reflect the feedback of the rival country $\left(\partial T_{h} / \partial \lambda\right.$ and $\partial T_{f} / \partial(1-\lambda)$ ) because each government considers how its counterpart changes its tax rate in response to changes in the distribution of firms. If these feedback terms were zero, the tax rates would be the same as those under the open-loop case (see Proposition.1-(i)). It can be verified in Appendix B that the feedback effect $\left(\partial T_{h} / \partial \lambda=\partial T_{f} / \partial(1-\lambda)=a\right)$ is positive. This means that the tax rate of a country should be directly proportional to the share of firms in that country.

The tax rates at the symmetric steady state in the Markov-perfect case is higher than that in the open-loop case. ${ }^{21}$ To see why, consider the situation where both countries stick to their open-loop tax schedules predetermined at the beginning until some point in time and country

${ }^{* 21}$ Note that $T_{i}^{m}\left(\lambda^{m}=1 / 2\right)-T_{i}^{o}\left(\lambda^{o}=1 / 2\right)=L^{2} a /[2(L-k Z)\{L+k(a-Z)\}]>0$ as long as $a>0$ and Assumption 5 holds. 
$h$ deviates from the schedule by increasing its tax rate. The tax increase of $h$ will cause some firms to move away from there to $f$. Under full commitment, country $f$ will continue to stick to the predetermined schedule so that such deviation of $h$ will never improve its payoff. In the absence of commitments, however, $h$ believes that $f$ will respond to this expansion of tax base by raising its tax rate according to the linear strategy. This consideration is captured by the feedback effect in the tax rates. The loss of firms in $h$ by raising its tax rate will be mitigated to some extent by the reaction of $f$. Thus, $h$ 's deviation from the open-loop schedule will increase its overall payoff. If $f$ anticipates this, it is also desirable for $f$ to deviate from the open-loop schedule.

In the open-loop case, when trade costs are low and the firms' incentive to agglomerate is strong, the tax rates at the symmetric state are negative so that both governments agree on the core-periphery outcomes. In the Markov-perfect case, however, competition becomes less severe because of the lack of commitment and the tax rates at the symmetric state may bring a higher payoff to both governments than those at the position of the core even when agglomeration forces are strong. The Pareto criterion of Assumption 4 implies that the dispersed configuration emerges in a wider range of trade costs.

Figs. 4 and 5 graphically illustrate the above discussions. Parameter values are $L=1$, $I=5, k=0.5$ in Fig. 4 and $k=1$ in Fig. 5. The tax and payoff of country $f$ have a mirror image. When parameter $k$ is small and thus tax adjustment costs $\left(-k T_{i}^{2} / 2\right)$ are less severe, the tax rate and the tax revenue $\left(L \lambda_{i} T_{i}\right)$ at the symmetric state become higher. ${ }^{222}$ In this case, the symmetric state generates a higher payoff than the agglomeration rent (Fig. 4-(b)) and emerges in equilibrium whatever trade costs may be by Assumption 4. When $k$ becomes larger and the motive of tax smoothing is strong, the tax rate and the tax revenue become lower. The symmetric state may become less desirable than the concentrated states (Fig. 5-(b)). The core-periphery patterns are observed in equilibrium when trade costs are in between the two bifurcations of tax competition $\left(\tau \in\left(\tau_{1}^{m}, \tau_{2}^{m}\right)\right)$ where the agglomeration rent is large. At the expense of firms, the governments' payoff at the symmetric state under MPNE is higher than that under OLNE.

\footnotetext{
${ }^{* 22}$ It can be checked that $\mathrm{d}\left(a_{2}^{m}\right) / \mathrm{d} k<0$ and $\mathrm{d}\left[T_{i}^{m}\left(\lambda^{m}=1 / 2\right)\right] / \mathrm{d} k<0$.
} 
(a)

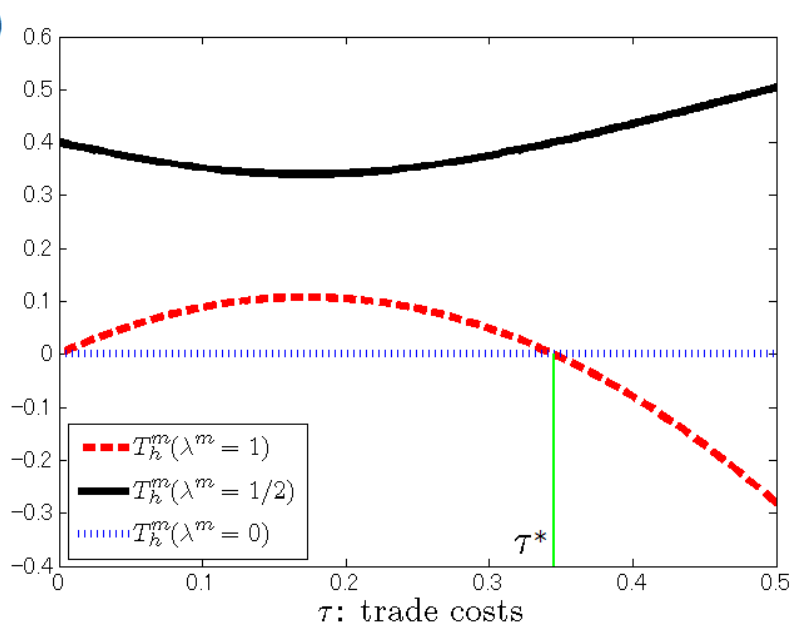

(b)

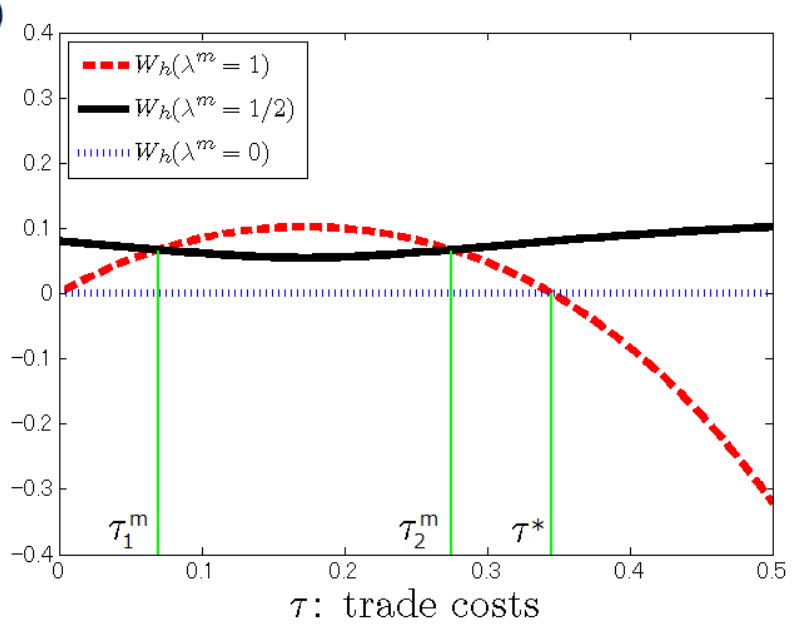

Fig. 4. Country $h$ 's (a) tax rate and (b) payoff at the steady state under MPNE with small $k$. 
(a)

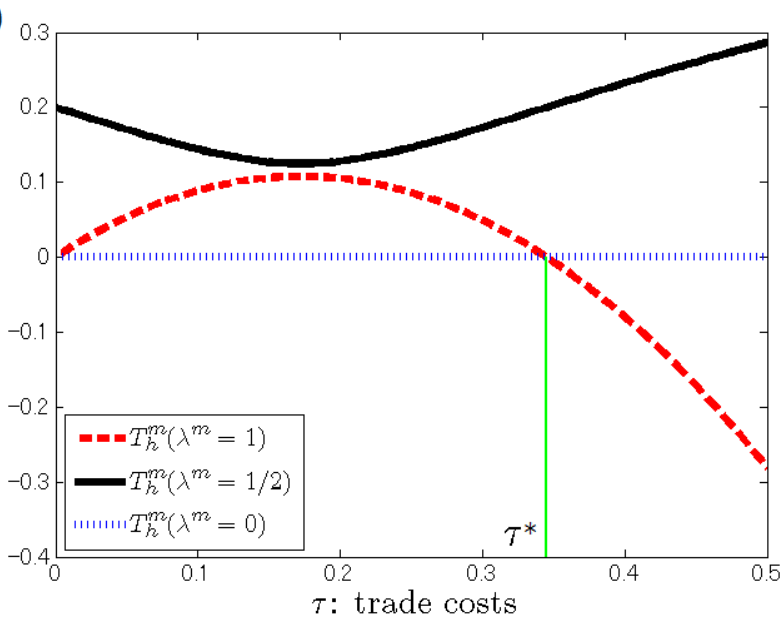

(b)

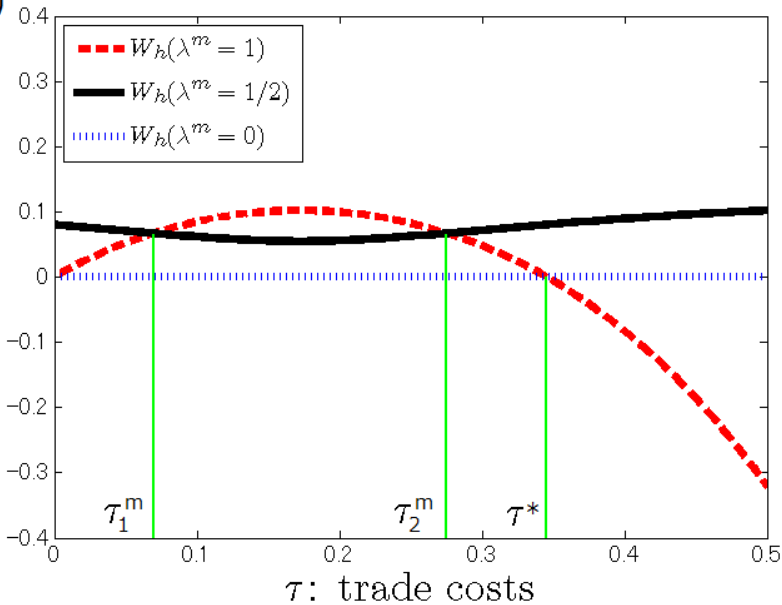

Fig. 5. Country $h$ 's (a) tax rate and (b) payoff at the steady state under MPNE with large $k$

Therefore, the following proposition is obtained:

Proposition 2. The MPNEs are characterized in the following way (except for the nongeneric cases: $\tau=\tau^{*}$ or $Z=0$ ).

(i) If $0<k \leq(2-\sqrt{2} \sqrt[4]{3}) L / \bar{Z} \approx 0.14 L / \bar{Z}$, the symmetric configuration is the only stable steady state no matter what trade costs may be. The tax rates at the steady state are given by

$$
T_{h}^{m}\left(\lambda^{m}=\frac{1}{2}\right)=T_{f}^{m}\left(\lambda^{m}=\frac{1}{2}\right)=\frac{L\left(Z-a_{2}^{m}\right)}{2\left[k\left(Z-a_{2}^{m}\right)-L\right]},
$$


where

$$
a_{2}^{m}=\frac{1}{3 k}\left[L+k Z+\sqrt{(L+k Z)^{2}-6 k L Z}\right]>0 .
$$

(ii) If $(2-\sqrt{2} \sqrt[4]{3}) L / \bar{Z}<k<(2-\sqrt{3}) L / \bar{Z}$, there are two cases:

(ii-i) If trade costs are sufficiently high $\left(\tau \geq \tau_{2}^{m}\right)$ or sufficiently low $\left(\tau \leq \tau_{1}^{m}\right)$, the symmetric configuration is the only stable steady state and the tax rates at the steady state are given by

$$
T_{h}^{m}\left(\lambda^{m}=\frac{1}{2}\right)=T_{f}^{m}\left(\lambda^{m}=\frac{1}{2}\right)=\frac{L\left(Z-a_{2}^{m}\right)}{2\left[k\left(Z-a_{2}^{m}\right)-L\right]} .
$$

(ii-ii) If trade costs are intermediate $\left(\tau_{1}^{m}<\tau<\tau_{2}^{m}\right)$, both the symmetric and concentrated configurations are stable steady states and the tax rates at each steady state are given by

$$
\begin{aligned}
& \text { Case } \lambda^{m}=0: T_{h}^{m}\left(\lambda^{m}=0\right)=0, \quad T_{f}^{m}\left(\lambda^{m}=0\right)=\frac{Z}{2}, \\
& \text { Case } \lambda^{m}=\frac{1}{2}: T_{h}^{m}\left(\lambda^{m}=\frac{1}{2}\right)=T_{f}^{m}\left(\lambda^{m}=\frac{1}{2}\right)=\frac{L\left(Z-a_{2}^{m}\right)}{2\left[k\left(Z-a_{2}^{m}\right)-L\right]}, \\
& \text { or } \\
& \text { Case } \lambda^{m}=1: T_{h}^{m}\left(\lambda^{m}=1\right)=\frac{Z}{2}, \quad T_{f}^{m}\left(\lambda^{m}=1\right)=0,
\end{aligned}
$$

where $\tau_{1}^{m}$ and $\tau_{2}^{m}$ are the solutions of $Z=(2-\sqrt{2} \sqrt[4]{3}) L / k$.

\section{Proof. See Appendix.}

Dynamic tax competition between governments that have no commitment leads to increases in their taxes at the symmetric state and thereby acts as a dispersion force. Especially when the adjustment of tax is not so costly (small $k$ ), sharing firms between countries is more desirable than collecting all the firms even when trade costs are intermediate and the agglomeration rent is large. This result is in stark contrast to the results from OLNE and from the existing literature that obtain the superiority of the core in a static setting (Baldwin and Krugman (2004); Borck and Pflüger (2006)). In the fully dynamic model, the credibility of policies significantly changes the result of tax competition.

The implication of MPNE that the lack of commitment gives governments a higher tax rate may explain the recent corporate tax policies of France. France has been one of the highestcorporate-tax countries in the EU since the mid-2000s, while at the same time it has been one of the most strong opponent of the world's lowest corporate tax rate of Ireland and has also 
been one of the biggest supporter of tax harmonization in the EU (see, e.g., Mitchell (2009); Stewart (2011)). Part of reason for the high tax in France may be that France has urged other countries to increase their tax rate and thereby expected to lessen losses from the relocation of domestic firms to low-tax countries. It is also worth noting that the direction of tax policies in France is sometimes subject to change (e.g., the regime change in 2012), which indicates that commitment is not so stringent. This story follows exactly what happens in MPNE.

Not only at the steady state, but also in the interim, the tax rate at the symmetric state under MPNE is higher than that under OLNE. Fig. 6 shows the transition paths with the same trade costs $\tau=0.4$ as in Fig. 3-(a). Initial conditions and other parameter values are also the same: $\lambda_{0}=0.7, L=1, I=5, k=1$, and $\rho / \gamma=0$. Unlike the open-loop case, the coreperiphery patterns exhibit no transition dynamics (see Appendix B for details). Because of the subgame perfectness of MPNE, even amidst unexpected shocks, governments optimally alter their taxes according to the linear Markov-perfect strategies.

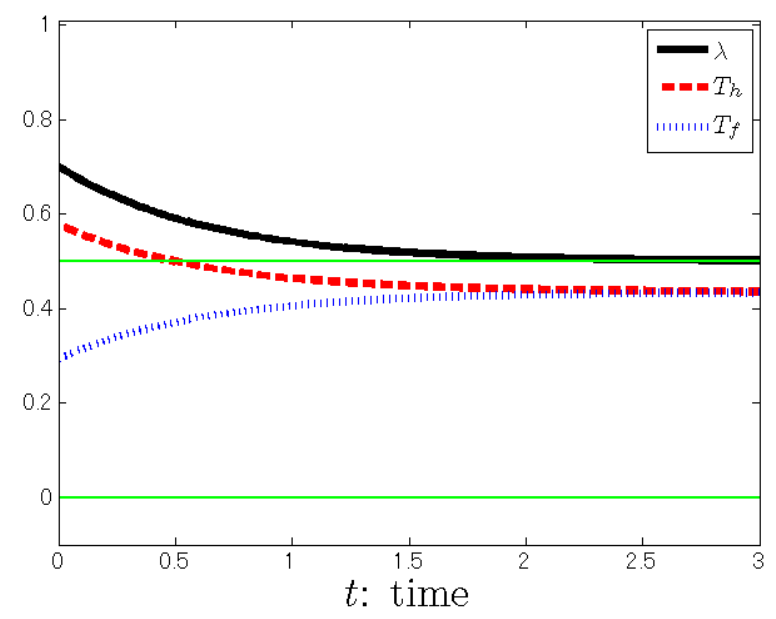

Fig. 6. Transition path under MPNE with the same trade costs as in Fig. 3-(a). 


\subsection{Discussion: What if firms are forward looking?}

The analysis has so far dealt with the situation where firms choose their location by looking at their current payoffs (the migration equation (6-1)). This subsection briefly argues that the main results would remain unchanged if firms are forward looking. Though a full characterization of far-sighted firms is the outside scope of the paper, I can examine some stylized cases.

The forward-looking behavior of firms is already reflected to some degree in the migration equation. The speed of adjustment $\gamma$ captures to what extent firms value their future payoffs because the larger $\gamma$ helps firms reach the stable steady state more quickly and thus makes firms focus only on the long-run outcome. ${ }^{.23}$ With this interpretation in mind, two cases are examined: in the one case firms are very far-sighted $(\gamma=\infty)$ and in the other case they discount their future payoffs to a certain extent $(\gamma \in(0, \infty)$.). 24

The case of $\gamma=\infty \quad$ In this case, the firms reach the stable steady state in a moment and therefore the governments also care solely about it regardless of their discount rate $\rho$. The dynamic tax game reduces to the static game. 255 This means that the governments choose their tax rate once and it does not matter whether or not they commit. As shown in the formal analysis in Appendix C, the results are summarized as follows. When trade costs are high, the dispersed configuration is the equilibrium one. When trade costs are low, however, the core-periphery pattern is the equilibrium one where the country that has more firms at the beginning of the game becomes the core. Since there is no transition path, what matters here is in which state the game starts. In this sense, the initial state acts as an equilibrium selection device. These location patterns are the same as those in the open-loop case discussed in Section 4.1 except for the role of the initial state and are also consistent with many of the existing studies on agglomeration and tax competition (e.g., Baldwin and Krugman (20)(1));

*23 The formal dynamic analysis of the new economic geography model by Oyama (2009b) shows that a sufficiently high speed of adjustment and a sufficiently low future discount rate of firms give the same result.

*24 The very myopic firms, which values the today's payoff most, can be represented as the almost zero speed of adjustments $\gamma=0$, in which case the firms stay in the initial state. The governments set their tax rate by considering only the initial location of firms.

*25 At the steady state, condition (6-3) for the optimality of the open-loop strategies (or (7) for the optimality of the Markov-perfect strategies) becomes: $(\rho / \gamma-Z) \mu_{h}=(L / \gamma) T_{h}$. When $\gamma=\infty$, the condition holds for $\mu_{h}=0$. The zero co-state variable means that the current strategies of agents do not affect future payoffs and makes the analysis static. 
Borck and Pflüger (2006)).

The case of $\gamma \in(0, \infty)$ If the governments are very far-sighted $(\rho \simeq 0)$, the degree of friction $\rho / \gamma$ is sufficiently close to zero as in Assumption 3 and the results of the main analysis hold. Consider the situation where the degree of friction is not so small. In this case, it is expected that the analysis yields similar results to those under the sufficiently small degree of frictions. It can be verified that the Markov-perfect strategies gives the governments a larger incentive to tax at the symmetric steady state than the open-loop strategies. 26 Therefore, the dispersed configuration may arise in a wider range of trade costs in the Markov-perfect equilibrium than in the open-loop equilibrium as in Proposition 1 and 2. 27 The main results under Assumption $3(\rho / \gamma \simeq 0)$, in particular, the importance of commitment aspect, would carry over to a more general case $(\rho / \gamma \in(0, \infty))$.

In a complete dynamic analysis which rigorously considers forward-looking behavior of governments and firms, government commitment toward both rival governments and firms can be important. Since the expectations of both sides interact, multiple equilibria may occur for a broad range of parameters. Commitment aspect as well as initial conditions may be crucial in equilibrium selection. One possible way to deal with such indeterminacy is to introduce asymmetries of market size and trade costs and utilize 'potential methods' as in Oyama (2009a). Further research is needed in this area.

\section{Conclusion}

Previous studies on agglomeration and tax competition deal mainly with static situations that imply that the initial industrial location matters and the core maintains its initially advantageous status. This paper contributes to this literature by introducing fully dynamic strategic interactions between governments.

This paper has considered OLNE and MPNE, contrasting equilibrium concepts in the sense that the former presumes full commitment of governments and the latter does not. As a result of tax competition under open-loop strategies, a dispersed spatial configuration emerges when trade costs are high, while when they are low, an agglomerated configuration appears.

\footnotetext{
${ }^{* 26}$ Note that $T_{i}^{m}\left(\lambda^{m}=1 / 2\right)-T_{i}^{o}\left(\lambda^{o}=1 / 2\right)=L^{2} a /[2\{L+k(\rho / \gamma-Z)\}\{L+k(\rho / \gamma+a-Z)\}]>0$ as long as $a>0$ and Assumption 5 holds.

*27 Unlike the case of $\rho / \gamma \simeq 0$, since the governments put emphasis on the way to the steady state, the initial state would starts to matter in determining which country will be the core.
} 
However, if the governments adopt Markov-perfect strategies, the dispersed configuration may be observed regardless of trade costs (note that the agglomerated configuration may also happen under low trade costs). The conclusion of the superiority of the core in the existing literature still holds in the dynamic model when the governments have full commitment, but the initial position is no longer important. Instead, the expectations of governments are essential in determining the core. The result that Markov-perfect strategies insulate the industrial firms from locating together especially when agglomeration tendencies are prevailing is simply because a lack of government commitment to their tax policies induces the governments to raise their tax rates, while an enormous decrease in tax is needed to convince firms to relocate.

These results suggest that, to become the winner of tax competition, it is necessary for a government to make foreign rivals expect that it is committed to its tax policies. This may explain why Ireland has succeeded in hosting large multinational enterprises. However, fully credible policies are not free from problems; they do not guarantee optimality once any unexpected events strike the economy. As an example, it may have been desirable if Ireland had modified its tax schedule when it faced financial collapse in 2010.

\section{Acknowledgement}

I deeply acknowledge Jota Ishikawa and Taiji Furusawa for their invaluable advice and continuous encouragement. I am also indebted to Daisuke Oyama whose suggestions greatly improved the analysis. Thanks are also due to Naohito Abe, Richard Baldwin, Shota Fujishima, Hideshi Itoh, Gang Li, Jim Markusen, Kiminori Matsuyama, Toshihiro Okubo, Tetsuya Saito, Etsuro Shioji, E.Young Song, Yoichi Sugita, and seminar and meeting participants at Hitotsubashi University, Otaru University of Commerce, University of Toyama, Sogang University and Toyo University for their helpful comments. Advice on academic writing from Philip MacLellan was extremely useful. All remaining errors are mine. Financial support from Grant-in-Aid for JSPS Fellows is gratefully acknowledged. 


\section{Appendix}

\section{Appendix A. Proof of Proposition 1.}

First, I derive the system of differential equations that characterize the economy. Then, I confirm that the symmetric state is the saddle stable when trade costs are high, and that the concentrated states are stable when trade costs are low.

By combining the necessary conditions for $h,(6-1),(6-2)$ and (6-3) with the corresponding conditions for $f$, the dynamic system is obtained as follows:

$$
\begin{aligned}
& \frac{\dot{\lambda}}{\gamma}=Z\left(\lambda-\frac{1}{2}\right)-\left(T_{h}-T_{f}\right), \\
& k \dot{T}_{h}=L(2 \gamma Z-\rho) \lambda+k(\rho-\gamma Z) T_{h}+\gamma L T_{f}-\frac{\gamma L Z}{2}+\gamma\left(v_{h}^{1}-v_{h}^{2}\right), \\
& k \dot{T}_{f}=L(\rho-2 \gamma Z) \lambda+\gamma L T_{h}+k(\rho-\gamma Z) T_{f}+L\left(\frac{3 \gamma Z}{2}-\rho\right)-\gamma\left(v_{f}^{1}-v_{f}^{2}\right) .
\end{aligned}
$$

To verify that the system depends only on a ratio between $\rho$ and $\gamma$, I apply the change of variables: $\lambda^{\prime}(t)=\lambda(t / \gamma), T_{h}^{\prime}(t)=T_{h}(t / \gamma)$ and $T_{f}^{\prime}(t)=T_{f}(t / \gamma)$. The system can be rewritten as the following:

$$
\begin{aligned}
& \dot{\lambda}^{\prime}=Z\left(\lambda^{\prime}-\frac{1}{2}\right)-\left(T_{h}^{\prime}-T_{f}^{\prime}\right), \\
& k \dot{T}_{h}^{\prime}=L\left(2 Z-\frac{\rho}{\gamma}\right) \lambda^{\prime}+k\left(\frac{\rho}{\gamma}-Z\right) T_{h}^{\prime}+L T_{f}^{\prime}-\frac{L Z}{2}+\left(v_{h}^{1}-v_{h}^{2}\right), \\
& k \dot{T}_{f}^{\prime}=L\left(\frac{\rho}{\gamma}-2 Z\right) \lambda^{\prime}+L T_{h}+k\left(\frac{\rho}{\gamma}-Z\right) T_{f}^{\prime}+L\left(\frac{3 Z}{2}-\frac{\rho}{\gamma}\right)-\left(v_{f}^{1}-v_{f}^{2}\right) .
\end{aligned}
$$

Assumption 5 requires that the ratio (the degree of friction) is sufficiently close to zero:

$$
\begin{aligned}
& \dot{\lambda}^{\prime}=Z\left(\lambda^{\prime}-\frac{1}{2}\right)-\left(T_{h}^{\prime}-T_{f}^{\prime}\right), \\
& k \dot{T}_{h}^{\prime}=2 L Z \lambda^{\prime}-k Z T_{h}^{\prime}+L T_{f}^{\prime}+\left(v_{h}^{1}-v_{h}^{2}\right)-\frac{L Z}{2}, \\
& k \dot{T}_{f}^{\prime}=-2 L Z \lambda^{\prime}+L T_{h}^{\prime}-k Z T_{f}^{\prime}-\left(v_{f}^{1}-v_{f}^{2}\right)+\frac{3 L Z}{2} .
\end{aligned}
$$

When trade costs are high: $\tau>\tau^{*}$ or $Z<0 \quad$ In this case, as was discussed in Section 4.1, the tax rate and the instantaneous payoff of both countries at the symmetric steady state are 
positive and those at the concentrated steady state are non-positive. Thus, only the symmetric state is achieved in equilibrium. At the interior equilibrium, it holds that $v_{h}^{1}=v_{h}^{2}=v_{f}^{1}=v_{f}^{2}=$ 0 . The system can be rewritten in matrix form:

$$
\left[\begin{array}{c}
\dot{\lambda}^{\prime} \\
\dot{T}_{h}^{\prime} \\
\dot{T}_{f}^{\prime}
\end{array}\right]=\left[\begin{array}{ccc}
Z & -1 & 1 \\
2 L Z / k & -Z & L / k \\
-2 L Z / k & L / k & -Z
\end{array}\right]\left[\begin{array}{c}
\lambda^{\prime}-1 / 2 \\
T_{h}^{\prime}-T^{o}\left(\lambda^{o}=1 / 2\right) \\
T_{f}^{\prime}-T^{o}\left(\lambda^{o}=1 / 2\right)
\end{array}\right],
$$

where the tax rate at the steady state is given by

$$
T^{o}\left(\lambda^{o}=\frac{1}{2}\right)=\frac{L Z}{2(k Z-L)}>0 .
$$

To examine the stability, we check the determinant of the coefficient matrix.

$$
\left|\begin{array}{ccc}
Z & -1 & 1 \\
2 L Z / k & -Z & L / k \\
-2 L Z / k & L / k & -Z
\end{array}\right|=\frac{Z(3 L-k Z)(L-k Z)}{k^{2}} .
$$

Under Assumption 5 that $k$ is positive but small enough, the determinant is negative. This ensures that the matrix has one negative eigenvalue and two positive eigenvalues. Since the system has one state variable $\lambda^{\prime}$ and two control variables $T_{h}^{\prime}$ and $T_{f}^{\prime}$, the negative determinant implies the steady state is saddle stable. The transversality conditions $\lim _{t \rightarrow \infty} \exp (-\rho t) \mu_{h}=$ $\lim _{t \rightarrow \infty} \exp (-\rho t) \mu_{f}=0$ hold by construction. Since the trajectories of the variables continuously approach the steady state, the jump conditions have no relevance here.

When trade costs are low: $\tau<\tau^{*}$ or $Z>0 \quad$ In this case, only the concentrated steady states are possible because the payoff for both countries at the symmetric steady state is negative. The proof of the stability is in two steps. First I show that the co-state variables $\mu_{h}^{\prime}(t)=\mu_{h}(t / \gamma)$ and $\mu_{f}^{\prime}(t)=\mu_{f}(t / \gamma)$ satisfy the jump conditions (6-6), (6-7) for $h$ and their correspondents for $f$ for some $\eta$. Then I confirm the existence of the Lagrange multipliers for the boundary conditions, $v_{h}^{1}, v_{h}^{2}, v_{f}^{1}$ and $v_{f}^{2}$.

By using the necessary conditions, the migration equation can be written as a function of the co-state variables:

$$
\dot{\lambda}^{\prime}=\left(Z-\frac{2 L}{k}\right)\left(\lambda^{\prime}-\frac{1}{2}\right)+\frac{\gamma}{k}\left(\mu_{h}^{\prime}+\mu_{f}^{\prime}\right) .
$$

Suppose that $s$ is the time when the economy hits $\lambda^{\prime}=1$. The payoff at the symmetric steady state is negative; therefore, after the economy hits the boundary, it is optimal for both 
countries to keep their position. Thus, I obtain the following:

$$
\begin{aligned}
& \dot{\lambda}^{\prime}\left(s^{-}\right)=\frac{1}{2}\left(Z-\frac{2 L}{k}\right)+\frac{\gamma}{k}\left[\mu_{h}^{\prime}\left(s^{-}\right)+\mu_{f}^{\prime}\left(s^{-}\right)\right] \geq 0, \\
& \dot{\lambda}^{\prime}\left(s^{+}\right)=\frac{1}{2}\left(Z-\frac{2 L}{k}\right)+\frac{\gamma}{k}\left[\mu_{h}^{\prime}\left(s^{+}\right)+\mu_{f}^{\prime}\left(s^{+}\right)\right]=0 .
\end{aligned}
$$

The jump conditions require that $\eta_{h}^{1}(s)=\eta_{f}^{1}(s)=0, \mu_{h}\left(s^{-}\right)-\mu_{h}^{\prime}\left(s^{+}\right)=-\eta_{h}^{2}(s)$ and $\mu_{f}\left(s^{-}\right)-$ $\mu_{f}\left(s^{+}\right)=-\eta_{f}^{2}(s)$. The difference of these equations becomes:

$$
\begin{aligned}
0 \leq \dot{\lambda}^{\prime}\left(s^{-}\right)-\dot{\lambda}^{\prime}\left(s^{+}\right) & =\frac{\gamma}{k}\left[\mu_{h}^{\prime}\left(s^{-}\right)-\mu_{h}^{\prime}\left(s^{+}\right)+\mu_{f}^{\prime}\left(s^{-}\right)-\mu_{f}^{\prime}\left(s^{+}\right)\right] \\
& =-\frac{\gamma}{k}\left[\eta_{h}^{2}(s)+\eta_{f}^{2}(s)\right] .
\end{aligned}
$$

Since $\eta$ is non-negative, only $\eta_{h}^{2}(s)=\eta_{f}^{2}(s)=0$ satisfies the above condition. Thus, the jump conditions hold for $\eta_{h}^{1}(s)=\eta_{f}^{1}(s)=\eta_{h}^{2}(s)=\eta_{f}^{2}(s)=0 . \dot{\lambda}^{\prime}\left(s^{-}\right)=\dot{\lambda}^{\prime}\left(s^{+}\right)=0$ implies that $\lambda$ continuously reaches the boundary and remains there. The co-state variables will not change once the economy hits the boundary, so that the transversality conditions also hold.

From time $s$ onwards, the tax rate is determined so as to satisfy $\dot{\lambda}^{\prime}=Z(1-1 / 2)-\left(T_{h}^{\prime}-T_{f}^{\prime}\right)=$ 0 . Country $f$, which has no firms, chooses $T_{f}^{o}\left(\lambda^{o}=1\right)=0$. Thus country $h$ sets a positive tax rate $T_{h}^{o}\left(\lambda^{o}=1\right)=Z / 2$.

Finally, I check that the Lagrange multipliers $v$ satisfy the conditions. The multipliers for the left boundary are not binding so that I obtain $v_{h}^{1}=v_{f}^{1}=0$. Those for the right boundary $v_{h}^{2}$ and $v_{f}^{2}$ can be obtained by making $\dot{T}_{h}^{\prime}=\dot{T}_{f}^{\prime}=0$ and substituting the steady state values into (A.1h) and (A.1f):

$$
\begin{aligned}
& 0=k \dot{T}_{h}^{\prime}=2 L Z \cdot 1-k Z \cdot \frac{Z}{2}+L \cdot 0+\left(0-v_{h}^{2}\right)-\frac{L Z}{2}, \\
& \Rightarrow v_{h}^{2}=\frac{Z(3 L-k Z)}{2}, \\
& 0=k \dot{T}_{f}^{\prime}=-2 L Z \cdot 1+L \cdot \frac{Z}{2}-k Z \cdot 0-\left(0-v_{f}^{2}\right)+\frac{3 L Z}{2} . \\
& \Rightarrow v_{f}^{2}=0 .
\end{aligned}
$$

$v_{h}^{2}$ is positive as long as Assumption 5 holds.

\section{Appendix B. Proof of Proposition 2.}


First, I solve for the parameters in the linear Markov strategy, $a$ and $b$. Second, I compare the payoff at the three steady states for different levels of trade costs and eliminate Pareto inefficient states (if any) by Assumption 4. Finally, I confirm the stability of the selected steady states.

Derivation of the parameters $a$ and $b$ in equilibrium As in Appendix A, from the necessary conditions both for $h$ and $f$, the dynamics of the tax rate of $h$ is characterized as follows:

$$
k \dot{T}_{h}=L\left[\gamma\left(2 Z+\frac{\partial T_{f}}{\partial \lambda}\right)-\rho\right] \lambda+k\left[\rho-\gamma\left(Z+\frac{\partial T_{f}}{\partial \lambda}\right)\right] T_{h}+\gamma L T_{f}-\frac{\gamma L Z}{2}+\gamma\left(v_{h}^{1}-v_{h}^{2}\right) .
$$

I apply the change of variables: $\lambda(t)=\lambda^{\prime}(t / \gamma), T_{h}(t)=T_{h}^{\prime}(t / \gamma)$ and $T_{h}(t)=T_{h}^{\prime}(t / \gamma)$, and let $\rho / \gamma$ close to zero:

$$
k \dot{T}_{h}^{\prime}=L\left(2 Z+\frac{\partial T_{f}^{\prime}}{\partial \lambda}\right) \lambda^{\prime}-k\left(Z+\frac{\partial T_{f}^{\prime}}{\partial \lambda}\right) T_{h}^{\prime}+L T_{f}^{\prime}-\frac{L Z}{2}+v_{h}^{1}-v_{h}^{2} .
$$

Imposing the linear specification of the strategies $T_{h}^{\prime}=a \lambda^{\prime}+b_{h}$ and $T_{f}^{\prime}=a\left(1-\lambda^{\prime}\right)+b_{f}$ yields

$$
k \dot{T}_{h}^{\prime}=L(2 Z-a) \lambda^{\prime}-k(Z-a)\left(a \lambda+b_{h}\right)+L\left[a\left(1-\lambda^{\prime}\right)+b_{f}\right]-\frac{L Z}{2}+v_{h}^{1}-v_{h}^{2} .
$$

The motion of $T_{h}^{\prime}$ can be written in a different way:

$$
\dot{T}_{h}^{\prime}=\frac{\partial T_{h}^{\prime}}{\partial \lambda^{\prime}} \frac{\mathrm{d} \lambda}{\mathrm{d} t}=a\left[Z\left(\lambda^{\prime}-\frac{1}{2}\right)-\left(a \lambda^{\prime}+b_{h}\right)+\left\{a\left(1-\lambda^{\prime}\right)+b_{f}\right\}\right] .
$$

Combining (B.1) with (B.2) yields:

$$
\left[3 k a^{2}-2(L+k Z) a+2 L Z\right] \lambda^{\prime}-k a^{2}+\left[L+k\left(\frac{Z}{2}+2 b_{h}-b_{f}\right)\right] a+L b_{f}-k Z b_{h}-\frac{L Z}{2}+v_{h}^{1}-v_{h}^{2}=0
$$

which is an identity with respect to $\lambda \in[0,1]$. For $f$, an analogous expression can be obtained:

$$
\left[3 k a^{2}-2(L+k Z) a+2 L Z\right] \lambda^{\prime}-2 k a^{2}+\left[L+k\left(\frac{Z}{2}+2 b_{h}-2 b_{f}\right)\right] a-L b_{h}+k b_{f} Z-3 L Z+v_{f}^{1}-v_{f}^{2}=0
$$

I solve for $a$ by making the coefficient of $\lambda^{\prime}$ zero:

$$
\begin{aligned}
& 3 k a^{2}-2(L+k Z) a+2 L Z=0, \\
& \Rightarrow a_{1}^{m}=\frac{1}{3 k}\left[L+k Z-\sqrt{(L+k Z)^{2}-6 k L Z}\right], \quad a_{2}^{m}=\frac{1}{3 k}\left[L+k Z+\sqrt{(L+k Z)^{2}-6 k L Z}\right] .
\end{aligned}
$$


Assumption 5 suggests that both roots are real. I then derive the tax rates at each steady state. At the symmetric state, it holds that $v_{h}^{1}=v_{h}^{2}=0$ and $b_{h}=b_{f}=b$ by the symmetry of the system. From the identity (B.3), I can solve for $b$ :

$$
\begin{aligned}
& -k\left(a^{m}\right)^{2}+\left[N+k\left(\frac{Z}{2}+2 b-b\right)\right] a^{m}-\frac{N Z}{2}+L b-k Z b=0, \\
& \Rightarrow b^{m}=\frac{L Z-(k Z-2 L) a^{m}}{6\left[k\left(Z-a^{m}\right)-L\right]} .
\end{aligned}
$$

Thus

$$
T_{h}^{m}\left(\lambda^{m}=\frac{1}{2}\right)=T_{f}^{m}\left(\lambda^{m}=\frac{1}{2}\right)=a^{m} \cdot \frac{1}{2}+b^{m}=\frac{L\left(Z-a^{m}\right)}{2\left[k\left(Z-a^{m}\right)-L\right]} .
$$

As for the right boundary state, $f$ has no tax base and sets its tax rate at zero. Then, $f$ chooses its tax rate so as to keep the distribution stable $\left(\dot{\lambda}^{\prime}=Z(1-1 / 2)-\left(T_{h}^{\prime}-0\right)=\right.$ $Z / 2-T_{h}^{\prime}=0$ ). Parameter $b$ associated with the tax rate at the left boundary are determined in the following way:

$$
\begin{aligned}
& T_{h}^{m}\left(\lambda^{m}=1\right)=a^{m} \cdot 1+b_{c}^{m}=\frac{Z}{2} \quad \Rightarrow \quad b_{c}^{m}=\frac{Z}{2}-a^{m} . \\
& T_{f}^{m}\left(\lambda^{m}=1\right)=a^{m} \cdot 0+b_{p}^{m}=0 \quad \Rightarrow \quad b_{p}^{m}=0 .
\end{aligned}
$$

Ranking of payoffs at the steady states Next, I compare the payoff at the symmetric state with the state at the right boundary. It is easy to check that the tax rate at $\lambda^{m}=1 / 2$ for $a_{2}^{m}$ is higher than that for $a_{1}^{m}$ and it is smaller than the unconstrained tax rate $\left(0<T_{i}^{m}\left(\lambda^{m}=\right.\right.$ $\left.\left.1 / 2 ; a_{1}^{m}\right)<T_{i}^{m}\left(\lambda^{m}=1 / 2 ; a_{2}^{m}\right)<L / k=\operatorname{argmax} W_{i}(\lambda=1 / 2)\right)$. Thus $a_{2}^{m}$ always gives the higher payoff than $a_{1}^{m}$ does. Assumption 4 suggests that $a_{2}^{m}$ should be adopted when the symmetric equilibrium emerges. Denote $W_{h}\left(\lambda^{m}=1 / 2\right) \equiv L T_{h}\left(\lambda^{m}=1 / 2 ; a_{2}^{m}\right) / 2-k\left[T_{h}\left(\lambda^{m}=\right.\right.$ $\left.\left.1 / 2 ; a_{2}^{m}\right)\right]^{2} / 2$ and $W_{h}\left(\lambda^{m}=1\right) \equiv L Z / 2-k Z^{2} / 4$. A tedious calculation reveals ${ }^{\kappa 28}$

\footnotetext{
*28 Note that$$
W_{h}\left(\lambda^{m}=\frac{1}{2}\right)-W_{h}\left(\lambda^{m}=1\right)=\frac{(k Z-2 L)\left[5 k^{3} Z^{3}-2 k^{2}(15 L+2 \sqrt{D}) Z^{2}+2 k L(21 L+8 \sqrt{D}) Z-4 L^{2}(L+\sqrt{D})\right]}{8 k\left[5 k^{2} Z^{2}-4 k(5 L+\sqrt{D}) Z+L(17 L+8 \sqrt{D})\right]},
$$$$
\text { where } D \equiv(L+k Z)^{2}-6 k L Z \text {. The solutions of } W_{h}\left(\lambda^{m}=1 / 2\right)-W_{h}\left(\lambda^{m}=1\right)=0 \text { are } Z=(2 \pm \sqrt{2} \sqrt[4]{3}) 2 L / k \text {, }
$$
$2 L / k$ and $4 L / k$.
} 


$$
\begin{aligned}
& Z \leq \frac{(2-\sqrt{2} \sqrt[4]{3}) L}{k} \Rightarrow W_{h}\left(\lambda^{m}=1\right) \leq W_{h}\left(\lambda^{m}=\frac{1}{2}\right) \\
& \frac{(2-\sqrt{2} \sqrt[4]{3}) L}{k}<Z<\frac{(2-\sqrt{3}) L}{k} \Rightarrow W_{h}\left(\lambda^{m}=\frac{1}{2}\right)<W_{h}\left(\lambda^{m}=1\right) .
\end{aligned}
$$

Remembering $W_{h}\left(\lambda^{m}=0\right)=0$, when $0<k \leq(2-\sqrt{2} \sqrt[4]{3}) L / \bar{Z}$, it follows that:

$$
\text { If } 0<\tau<\tau_{\text {trade }} \Rightarrow W_{h}\left(\lambda^{m}=0\right)<W_{h}\left(\lambda^{m}=\frac{1}{2}\right), \quad W_{h}\left(\lambda^{m}=1\right) \leq W_{h}\left(\lambda^{m}=\frac{1}{2}\right) .
$$

And when $(2-\sqrt{2} \sqrt[4]{3}) L / \bar{Z}<k<(2-\sqrt{3}) L / \bar{Z}$, it follows that:

$$
\begin{aligned}
& \text { If } 0<\tau \leq \tau_{1}^{m} \Rightarrow W_{h}\left(\lambda^{m}=0\right)<W_{h}\left(\lambda^{m}=1\right) \leq W_{h}\left(\lambda^{m}=\frac{1}{2}\right) \\
& \text { If } \tau_{1}^{m}<\tau<\tau_{2}^{m} \Rightarrow W_{h}\left(\lambda^{m}=0\right)<W_{h}\left(\lambda^{m}=\frac{1}{2}\right)<W_{h}\left(\lambda^{m}=1\right), \\
& \text { If } \tau_{2}^{m} \leq \tau<\tau_{\text {trade }} \quad \Rightarrow W_{h}\left(\lambda^{m}=0\right)<W_{h}\left(\lambda^{m}=\frac{1}{2}\right), \quad W_{h}\left(\lambda^{m}=1\right) \leq W_{h}\left(\lambda^{m}=\frac{1}{2}\right) .
\end{aligned}
$$

The solution of $W_{h}\left(\lambda^{m}=1 / 2\right)-W_{h}\left(\lambda^{m}=1\right)=0$ which lies in $\tau \in\left(0, \tau_{\text {trade }}\right)$ is $Z=(2-$ $\sqrt{2} \sqrt[4]{3}) L / k$. Solving this equation for $\tau$ gives $\tau_{1}^{m}$ and $\tau_{2}^{m} . \tau_{2}^{m}\left(>\tau_{1}^{m}\right)$ is smaller than $\tau^{*}$, which is the positive solution of $Z=0$.

Stability of the symmetric state The boundary conditions are not binding so that I have $v_{h}^{1}=v_{h}^{2}=v_{f}^{1}=v_{f}^{2}=0$. To see that $a_{2}^{m}$ guarantees the stability of the symmetric state, I look at the slope of the migration equation:

$$
\dot{\lambda}^{\prime}=Z\left(\lambda^{\prime}-\frac{1}{2}\right)-\left(T_{h}^{\prime}-T_{f}^{\prime}\right)=\left(Z-2 a^{m}\right) \lambda^{\prime}+a^{m}-\frac{Z}{2} .
$$

$Z-2 a_{2}^{m}$ is negative regardless of $Z$ or $\tau$, which ensures stability. The fact that the state variable converges to a finite value implies that the co-state variables also do so. Thus the transversality conditions also hold. The jump conditions trivially holds for $\eta_{h}^{1}=\eta_{h}^{2}=\eta_{f}^{1}=$ $\eta_{f}^{2}=0$

Stability of the boundary states I focus on the situation where the economy hits the right boundary. I can show that jump conditions are satisfied in the same manner as in Appendix A. Consider the smaller root $a_{1}^{m}$ first. At $\lambda=1$, the conditions for the left boundary are not binding so that I obtain $v_{h}^{1}=v_{f}^{1}=0$. Substituting $a_{1}^{m}, b_{c}^{m}, b_{p}^{m}$ into (B.3h), I can derive the 
Lagrange multiplier of $h$ for the right boundary:

$$
\begin{aligned}
& -k\left(a_{1}^{m}\right)^{2}+\left[L+k\left(\frac{Z}{2}+2 b_{c}^{m}-b_{p}^{m}\right)\right] a_{1}^{m}+L b_{p}^{m}-k Z b_{c}^{m}-\frac{L Z}{2}-v_{h}^{2}=0 \\
& \Rightarrow v_{h}^{2}=\left(\frac{k Z}{2}-L\right) a_{1}^{m}+\frac{Z(3 L-k Z)}{2} .
\end{aligned}
$$

which is positive as long as $Z>0$ or $\tau<\tau^{*}$ and Assumption 5 holds. The multiplier of $f$ for the right boundary is derived from (B.3f):

$$
\begin{aligned}
& -2 k\left(a_{1}^{m}\right)^{2}+\left[L+k\left(\frac{3 Z}{2}+b_{c}^{m}-2 b_{p}^{m}\right)\right] a_{1}^{m}-L b_{c}^{m}+k b_{p}^{m} Z-3 L Z-v_{f}^{2}=0 \\
& \Rightarrow v_{f}^{2}=0 .
\end{aligned}
$$

$a_{1}^{m}$ brings the negative slope of the migration equation $\left(Z-2 a_{1}^{m}<0\right)$ so that there are no transition paths and the economy reaches the boundary in a moment. The transversality conditions trivially hold.

If the larger root $a_{2}^{m}$ is chosen, $v_{h}^{2}$ turns out to be negative so that the agglomerated distributions, as well as the dispersed distribution, are never achieved in equilibrium. Therefore, when the core-periphery patterns emerge in equilibrium, the smaller root $a_{1}^{m}$ and the associated $b_{c}^{m}$ and $b_{p}^{m}$ should be adopted.

\section{Appendix C. Analysis under very far-sighted firms.}

I consider the situation where the migration speed is infinitely high $(\gamma=\infty)$, i.e., firms care only about the long-run payoff. As mentioned in the text, the problem now reduces to an one-shot simultaneous game as in the literature. The game proceeds as follows. First, each government announces an tax rate simultaneously and non-cooperatively. Then, firms relocate to the country that affords a higher payoff in the steady states. The game should be solved backward. That is, the governments choose their tax rate to maximize their one-shot payoff while taking into account the steady-state distribution of firms. The economy without governments has two stable steady states, the dispersed state when trade costs are high and the agglomerated state when they are low (see Lemma). I treat these cases separately.

When trade costs are high: $\tau>\tau^{*}$ or $Z<0 \quad$ In this case, the stable steady state will be $\lambda$ 
that satisfies $\dot{\lambda} / \gamma=0$ :

$$
\begin{aligned}
& \frac{\dot{\lambda}}{\gamma}=Z\left(\lambda-\frac{1}{2}\right)-\left(T_{h}-T_{f}\right)=0, \\
& \Rightarrow \lambda=\frac{1}{2}+\frac{T_{h}-T_{f}}{Z} .
\end{aligned}
$$

By substituting this into the one-shot payoff of each government $\left(W_{i}=L \lambda_{i} T_{i}-k T_{i}^{2} / 2, i \in\right.$ $\{h, f\})$ and differentiating it with respect to its tax rate, I can obtain the response function of each government ( $h$ and $f$ respectively):

$$
\begin{aligned}
\left(\frac{2 L}{Z}-k\right) T_{h}+L\left(\frac{1}{2}-\frac{T_{f}}{Z}\right) & =0 \\
\left(\frac{2 L}{Z}-k\right) T_{f}+L\left(\frac{1}{2}-\frac{T_{h}}{Z}\right) & =0
\end{aligned}
$$

I solve these equations and obtain the Nash equilibrium tax rates and the eventual share of firms.

$$
T_{h}^{s}=T_{f}^{s}=\frac{L Z}{2(k Z-L)}, \quad \lambda^{s}=\frac{1}{2} .
$$

These are the same as in the open-loop case (Proposition 1-(i)).

When trade costs are low: $\tau<\tau^{*}$ or $Z>0 \quad$ In this case, the stable steady state will be either $\lambda=0$ or $\lambda=1$. Suppose that $\Delta u^{*}\left(\lambda_{0}\right)=Z\left(\lambda_{0}-1 / 2\right)-\left(T_{h}-T_{f}\right) \geq 0$ holds given the rival's tax rate and the initial state and country $h$ will achieve an agglomeration. Then $h$ will set its tax rate to the level where firms' delocation never occurs, i.e., $T_{h}$ that satisfies $\Delta u^{*}\left(\lambda_{0}\right)=0$, or it will attain the unconstrained maximum by choosing $T_{h}=\operatorname{argmax}\left[L T_{h}-k T_{h}^{2} / 2\right]=$ $L / 2$. Similar reasoning applies to the case of country $f$. The best response function of each government becomes:

$$
\begin{gathered}
T_{h}= \begin{cases}\min \left\{L / k, Z\left(\lambda_{0}-1 / 2\right)+T_{f}\right\}, & Z\left(\lambda_{0}-1 / 2\right)-\left(T_{h}-T_{f}\right) \geq 0, \\
0, & Z\left(\lambda_{0}-1 / 2\right)-\left(T_{h}-T_{f}\right) \leq-\varepsilon .\end{cases} \\
T_{f}= \begin{cases}\min \left\{L / k, Z\left(1 / 2-\lambda_{0}\right)+T_{h}\right\}, & Z\left(\lambda_{0}-1 / 2\right)-\left(T_{h}-T_{f}\right) \leq-\varepsilon, \\
0, & Z\left(\lambda_{0}-1 / 2\right)-\left(T_{h}-T_{f}\right) \geq 0 .\end{cases}
\end{gathered}
$$

where $\varepsilon$ is a sufficiently small positive constant, which excludes the indeterminacy of equilibrium tax rate. Since it always holds that $L / k>Z\left(\lambda_{0}-1 / 2\right)$ under Assumption 5, the Nash 
equilibrium tax rates are given by

$$
T_{h}^{s}=Z\left(\lambda_{0}-\frac{1}{2}\right), \quad T_{f}^{s}=0, \quad \lambda^{s}=1
$$

It is worth noting that the tax rate of the core country $T_{h}^{s}$ is inverted U-shaped in trade costs $\tau$ (see the definition of $Z$ in Section 2.4). The result is so called a 'race to the top'(Baldwin and Krugman (2004); Borck and Pflüger (2006)). 


\section{References}

Andersson, F. and Forslid, R. (2003). Tax competition and economic geography. Journal of Public Economic Theory, 5(2):279-303.

Baldwin, R. E. (2001). Core-periphery model with forward-looking expectations. Regional Science and Urban Economics, 31(1):21-49.

Baldwin, R. E., Forslid, R., Martin, P., Ottaviano, G. I., and Robert-Nicoud, F. (2003). Economic Geography and Public Policy. Princeton University Press, Princeton, NJ.

Baldwin, R. E. and Krugman, P. R. (2004). Agglomeration, integration and tax harmonisation. European Economic Review, 48(1):1-23.

Baldwin, R. E. and Okubo, T. (2014). Tax competition with heterogeneous firms. Spatial Economic Analysis, 9(3):309-326.

Borck, R. and Pflüger, M. (2006). Agglomeration and tax competition. European Economic Review, 50(3):647-668.

Brülhart, M., Jametti, M., and Schmidheiny, K. (2012). Do agglomeration economies reduce the sensitivity of firm location to tax differentials? Economic Journal, 122(563):10691093.

Charlot, S. and Paty, S. (2007). Market access effect and local tax setting: Evidence from french panel data. Journal of Economic Geography, 7(3):247-263.

Coulibaly, S. (2008). Empirical assessment of the existence of taxable agglomeration rents. HEC Lausanne, DEEP, D 巡 partement d'économ 巡 trie et d'économie politique.

Department of Finance of Ireland (2013). Ireland's international tax strategy. URL: http://wWw. finance.gov.ie/what-we-do/tax-policy/publications/ reports-research/irelands-international-tax-strategy.

Dockner, E., Jorgensen, S., Long, N., and Sorger, G. (2000). Differential Games in Economics and Management Science. Cambridge University Press, New York.

Forslid, R. and Ottaviano, G. (2003). An analytically solvable core-periphery model. Journal of Economic Geography, 3(3):229-240.

Fujita, M. and Thisse, J.-F. (2013). Economics of Agglomeration: Cities, Industrial Location, and Globalization. Cambridge University Press, New York, second edition.

Han, Y., Pieretti, P., Zanaj, S., and Zou, B. (2014). Asymmetric competition among nation states: A differential game approach. Journal of Public Economics, 119:71-79. 
Hartl, R. F., Sethi, S. P., and Vickson, R. G. (1995). A survey of the maximum principles for optimal control problems with state constraints. SIAM Review, 37(2):181-218.

Haufler, A. and Wooton, I. (2010). Competition for firms in an oligopolistic industry: The impact of economic integration. Journal of International Economics, 80(2):239-248.

Janeba, E. (2000). Tax competition when governments lack commitment: Excess capacity as a countervailing threat. American Economic Review, 90(5):1508-1519.

Keen, M. and Konrad, K. A. (2012). The theory of international tax competition and coordination. Working Paper of the Max Planck Institute for Tax Law and Public Finance.

Kenny, L. W. and Winer, S. L. (2006). Tax systems in the world: An empirical investigation into the importance of tax bases, administration costs, scale and political regime. International Tax and Public Finance, 13(2-3):181-215.

Kind, H. J., Knarvik, K. H. M., and Schjelderup, G. (2000). Competing for capital in a 'lumpy' world. Journal of Public Economics, 78(3):253-274.

Krugman, P. R. (1991). History versus expectations. Quarterly Journal of Economics, 106(2):651-667.

Ludema, R. D. and Wooton, I. (2000). Economic geography and the fiscal effects of regional integration. Journal of International Economics, 52(2):331-357.

Markusen, J. R. and Maskus, K. E. (2002). Discriminating among alternative theories of the multinational enterprise. Review of International Economics, 10(4):694-707.

Matsuyama, K. (1991). Increasing returns, industrialization, and indeterminacy of equilibrium. Quarterly Journal of Economics, 106(2):617-650.

Mitchell, D. J. (2009). The economics of tax competition: Harmonization vs. liberalization. Adam Smith Institute.

Ottaviano, G. I. (2001). Monopolistic competition, trade, and endogenous spatial fluctuations. Regional Science and Urban Economics, 31(1):51-77.

Ottaviano, G. I., Tabuchi, T., and Thisse, J.-F. (2002). Agglomeration and trade revisited. International Economic Review, 43(2):409-436.

Ottaviano, G. I. and Ypersele, T. V. (2005). Market size and tax competition. Journal of International Economics, 67(1):25-46.

Oyama, D. (2009a). Agglomeration under forward-looking expectations: Potentials and global stability. Regional Science and Urban Economics, 39(6):696-713.

Oyama, D. (2009b). History versus expectations in economic geography reconsidered. Journal of Economic Dynamics and Control, 33(2):394-408. 
Reynolds, S. S. (1987). Capacity investment, preemption and commitment in an infinite horizon model. International Economic Review, 28(1):69-88.

Rotemberg, J. J. (1982). Sticky prices in the united states. Journal of Political Economy, 90(6):1187-1211.

Stewart, J. (2011). Corporation tax: How important is the $12.5 \%$ corporate tax rate in ireland? Institute for International Integration Studies Discussion Paper 375, Trinity College Dublin.

Summers, L. H. (1981). Taxation and corporate investment: A q-theory approach. Brookings Papers on Economic Activity, 1981(1):67-140.

Thisse, J.-F. (2010). Toward a unified theory of economic geography and urban economics. Journal of Regional Science, 50(1):281-296. 